\title{
WestVirginiaUniversity
}

THE RESEARCH REPOSITORY @ WVU

Graduate Theses, Dissertations, and Problem Reports

1998

\section{Desire for thinness and desire for health in eighteen and nineteen- year-old females}

Monica Gene Andis

West Virginia University

Follow this and additional works at: https://researchrepository.wvu.edu/etd

\section{Recommended Citation}

Andis, Monica Gene, "Desire for thinness and desire for health in eighteen and nineteen-year-old females" (1998). Graduate Theses, Dissertations, and Problem Reports. 899.

https://researchrepository.wvu.edu/etd/899

This Thesis is protected by copyright and/or related rights. It has been brought to you by the The Research Repository @ WVU with permission from the rights-holder(s). You are free to use this Thesis in any way that is permitted by the copyright and related rights legislation that applies to your use. For other uses you must obtain permission from the rights-holder(s) directly, unless additional rights are indicated by a Creative Commons license in the record and/ or on the work itself. This Thesis has been accepted for inclusion in WVU Graduate Theses, Dissertations, and Problem Reports collection by an authorized administrator of The Research Repository @ WVU. For more information, please contact researchrepository@mail.wvu.edu. 


\title{
DESIRE FOR THINNESS AND DESIRE FOR HEALTH IN EIGHTEEN AND NINETEEN YEAR OLD FEMALES
}

\author{
Monica Andis
}

\begin{abstract}
Thesis submitted to the Faculty of West Virginia University in partial fulfillment of the requirements for the degree of

Master of Science

in

Family and Consumer Sciences
\end{abstract}

Mary K. Head, Chair

Carol Markstrom

Shirley Lazorchak

October 1, 1998

Morgantown, West Virginia

Key words: Body Image, Adolescent Dietary Behavior 


\section{ACKNOWLEDGEMENTS}

I would like to thank Dr. Carol Markstrom for helping me define my research goals and for helping me stay focused! I would like to thank both Dr. Markstrom and Dr. Shirley Lazorchak for their insistence on excellence in research, and for their encouragement, support, and time in serving on my committee.

Although he was not on my research committee, Dr. Zafar Nomani still gave graciously of his time and knowledge in statistical analysis. Dr. Nomani has been an unfailing source of support and encouragement to me during my years in the Family and Consumer Sciences nutrition program, and I have enjoyed his personal anecdotes as much as his scientific expertise.

The greatest pleasure I have had during my tenure as a student has been the experience of learning from and working with Dr. Mary Head, my major professor. Dr. Head's standards of excellence, her superb teaching, her professional and personal support, and her warmth have impressed, inspired, and sustained me greatly. I offer her a heartfelt thanks for a wonderfully satisfying academic experience. 


\section{TABLE OF CONTENTS}

Page

ACKNOWLEDGEMENTS ..................................... ii

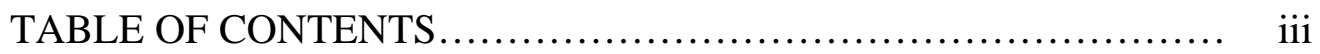

LIST OF TABLES.............................................. vi

INTRODUCTION ................................................ 1

Objectives.............................................. 3

REVIEW OF LITERATURE.................................... 4

Overview.................................................. 4

Desire For Thinness........................................ 5

Evidence For Cultural Standards of Thinness............ 5

Evidence For Female Susceptibility to Cultural

Messages About Appearance.......................... 5

Evidence For Desire For Thinness in Female

Adolescents and Young Adults......................... 7

Desire For Health....................................... 8

Evidence For Cultural Messages of Health............. 8

Evidence For Desire For Health in Female

Adolescents and Young Adults........................ 9

Predictor Variables....................................... 12

Body Image Satisfaction.......................... 12

Weight perception Accuracy......................... 14

Self-esteem......................................... 15

Socioeconomic Status................................ 17

Food Management Behavior........................... 19

Summary................................................ 24

MATERIALS AND METHODS ................................. 25

Overview............................................. 25

Procedures............................................... 25 
Questionnaire........................................... 25

Subjects.............................................. 25

Experimental Design........................................ 26

Independent Variables.................................... 27

Body Image Variables............................. 27

Self-esteem Variable................................. 28

Socioeconomic and Demographic Variables............ 29

Food Management Variables........................... 30

Dependent Variable......................................... 31

Additional Statistical and Descriptive Data................... 33

Body Image Variables.............................. 33

Demographic Variables............................. 35

Food Management Variables......................... 36

RESULTS................................................ 40

Demographic Information................................. 40

Discriminate Analysis................................... 40

Comparison Groups................................ 40

Predictor Variables......................................... 40

Discriminate Analysis Results............................... 42

General Results.................................. 42

Results With Significant Predictor Variables............ 46

Other Statistical Analyses and Descriptive Data................. 51

Desire For Thinness, Body Weight Satisfaction,

And Weight Loss Desired........................... 51

Self-esteem and Desire For Weight Loss............... 54

Food Management Behavior.......................... 56

Body Image Motivations............................ 63

Desire For Health................................. 63

DISCUSSION .................................................... 67

Discriminate Analysis................................... 67

Body Image Variables............................... 67

Self-esteem Variable.................................. 68

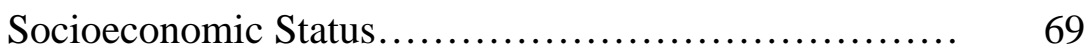

Food Management Group.......................... 69

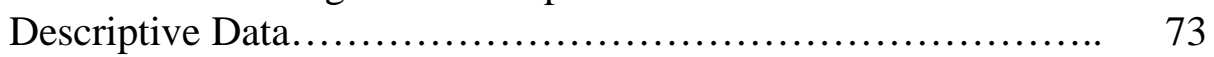

Desire For Thinness and Health...................... 73

Desire For Thinness and Weight Loss.................. 75 
Relationship of Body Weight Satisfaction

To Dieting Behavior.

Desire For Weight Loss, Desire For Thinness, and

Use of Unhealthy Food Management Behaviors.......... 76

Implications and Conclusions............................. 77

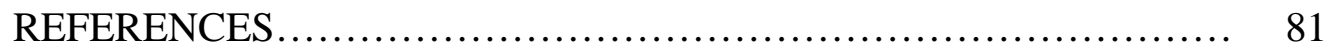

APPENDICES................................................. 88

Appendix A: Survey Questionnaire........................ 89

Appendix B: Survey Questionnaire, coded..................... 97

Appendix C: Institutional Review Board Approval and

Letter of Introduction to Students................ 108

Appendix D: Permission Form Letters and Permission

Letters From Surveyed Institutions.............. 112

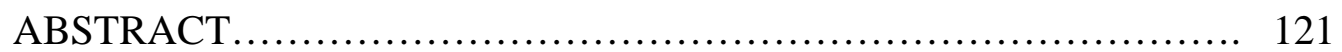

CURRICULUM VITAE....................................... 123

APPROVAL OF EXAMINING COMMITTEE....................... 124 


\section{LIST OF TABLES}

Page

Table 1 Total number, educational level, residency, and racial make-up of subjects in the sample population

Table 2 Number of subjects assigned to the four comparison or dependent variable groups...

Table 3 Strength of statistical contribution of predictor variables to discriminant analysis model as measured by Wilks' Lambda, partial Lambda, and F-remove ratio values. ...

Table 4 Classification matrix or percent of correct classification of girls in comparison groups by the predictor variables of father's education, religiosity, weight perception accuracy, food management group, and self-esteem group

Table 5 Significance of Eigenvalue, canonical R, Wilks'Lambda, and chi square tests with successive roots removed, in the prediction of comparison groups by the predictor variable model of father's education, religiosity, weight perception accuracy, food management group, and self-esteem group

Table 6 Statistical contribution of the predictor variables of weight perception accuracy, food management group, religiosity, father's education, and self-esteem group to each discriminant function or root as determined by standardized coefficients for canonical variables

Table 7 Differences among comparison groups characterized by the means of the canonical variables of the three roots or discriminant functions.

Table 8 Weight perception accuracy of girls in the four comparison groups of desiring thinness, desiring health, desiring both thinness and health, and desiring neither thinness nor health..... 
Table 9 Actual weight/ size ranges, average BMI values, and BMI ranges of girls in comparison groups...........................

Table 10 Food management strategies of dieting, dieting and watching, watching only, and neither dieting nor watching (defined as food management groups), used by girls in the four comparison groups of desiring thinness, desiring health, desiring both thinness and health, and desiring neither thinness nor health..........................

Table 11 Actual weight/size range of girls who desired thinness..........

Table 12 Actual weight/size range of girls who desired thinness..........

Table 13 Distribution of self-esteem scores (categorized by self-esteem groups) among girls who desired different amounts of weight loss

Table 14 Food management strategies of dieting, dieting and watching, watching only, and neither dieting nor watching (defined as food management groups), chosen by subjects who desired different amounts of weight loss...................

Table 15 Actual size/weight ranges and food management behaviors of dieting, dieting and watching, watching only, and neither dieting nor watching (defined as food management group) used by girls desiring unnecessary weight loss..................

Table 16 Different motivations for dieting used by girls in the four comparison groups of desiring thinness, desiring health, desiring both thinness and health, and desiring neither thinness nor health..........................................

Table 17 Different motivations for watching what they ate used by girls in the four comparison groups of desiring thinness, desiring health, desiring both thinness and health, and desiring neither thinness nor health 
Table 18 Specific food management behaviors preferred or used most frequently by dieters and dieter/watchers that were considered to be unhealthy behaviors...........................

Table 19 Body image motivations among girls in the four comparison groups of desiring thinness, desiring health, desiring both thinness and health, and desiring neither thinness nor health.........................................

Table 20 Number of girls in the sample population who subscribed to different motivations that may be associated with desire or lack of desire for health...................................... 


\section{INTRODUCTION}

Over the last two decades, researchers have reported that women and female adolescents are being exposed to an increasingly thin cultural standard of appearance (Garner, Garfinkel \& Schwartz, 1980; Guillen \& Barr, 1994; Silverstein, Perdue, Peterson, \& Kelly, 1986;). Acceptance of this standard may be leading to problems in the female population such as decreases in self-esteem and body image satisfaction, and increases in eating disorders and unhealthy weight management practices (Collins, 1988; Garner \& Garfinkel, 1980; Kelly, Patten, \& Johannes, 1982; Killen et al., 1993).

At the same time, women and adolescents have been exposed to another cultural message about appearance that communicates the importance of maintaining a healthy body weight through proper nutrition and exercise (Food and Nutrition Board \& National Research Council on Foods Joint statement, 1973). This message has been promoted by public health educators who are trying to reduce the incidence of obesity and chronic disease in the population (Garrison, Klesges, \& Applegate, 1996; Jannot, 1996; Owen, 1985).

Concerns about weight and diet are often cited as evidence of cultural pressures for thinness in female adolescents (Lundholm \& Littrell, 1986; McBride, 1986; Searles, Terry \& Amos, 1986). Evidence indicates, however, that female adolescents are receiving the message about health as well; and in some cases concerns about diet and weight are motivated by health concerns instead of or in addition to concerns about thinness (Nichter, Ritenbaugh, Nichter, Vuckovic, \& Aiken, 1995). There is also evidence that some female adolescents equate thinness with health, thereby combining these dual messages (Magilvy, McMahon, Bachman, Roark, \& 
Evenson, 1987; Saltonstall, 1993).

Researchers and educators have stated that female adolescent concerns about weight are leading to an epidemic of unhealthy dieting practices (Collins, 1989; Damhorst, Littrell, \& Littrell, 1987; Killen et al., 1993; Moreno, 1995). Incidence of dieting may be overstated, however, as the accuracy of some of the methodology used in documenting female adolescent dieting behavior has been questioned. Further, what adolescent females mean by the term "dieting" has not been well defined (Nichter et al., 1995). Thus, it is not clear from the evidence how many adolescents are motivated by desire for thinness or health, how many diet, and what female adolescent dieting means in terms of food management behavior. Answers to the following questions may help clarify some of these issues:

- What is the true incidence of adolescent girls who desire thinness in order to conform to the cultural ideal?

- Can a group of adolescent girls motivated by a desire for health be separately identified?

- How many adolescent girls desire both thinness and health?

- How many adolescent girls desire neither thinness nor health?

- Can adolescent girls who fit into the above groups be distinguished from one another by differences in their food management behaviors?

- What other variables might distinguish these groups from one another?

Examination of some of the possible variables that distinguish these groups from one another may be of value in contributing information toward the formulation of effective health education strategies for adolescent females. 


\section{Objectives}

1. To determine whether desire for thinness is a significant motivation in eighteen and nineteen year old female adolescents in the north-central West Virginia region.

2. To discover whether desire for health is a significant motivation in eighteen and nineteen year old female adolescents in the north-central West Virginia region.

3. To determine incidence of use of healthy and unhealthy food management behaviors in eighteen and nineteen year old female adolescents in the north-central West Virginia region.

4. To discover whether female adolescents who desire thinness, health, both thinness and health, and neither thinness nor health, can be distinguished from one another by differences in their body image satisfaction, self-esteem, socioeconomic status (SES), and food management behaviors.

Hypothesis: body image satisfaction, high self-esteem, high SES, and healthy food management behaviors should predict girls who desire health, while body image dissatisfaction, low self-esteem, low SES, and unhealthy food management behaviors should predict girls who desire thinness. 


\section{REVIEW OF LITERATURE}

\section{Overview}

Researchers have shown that thinness is promoted in our society as the preferred standard of appearance for females (Garner et al., 1980; Guillen \& Barr, 1994; Silverstein et al., 1986). Adolescent females have been shown to be particularly susceptible to this standard because appearance is the major determinant of social acceptance and identity during adolescence (Zakin, Blyth, \& Simmons, 1984; Searles et al., 1986; Prokhorov, Perry, Kelder, \& Klepp, 1993). Some researchers have found higher rates of body image dissatisfaction, dieting behavior, and eating disorders among adolescent females compared to the rest of the population, and have attributed these findings to adolescent females' greater susceptibility to cultural pressures for thinness (Collins, 1988; Mueller et al., 1995; Searles et al., 1986). Yet, cultural messages of thinness are not the only messages related to appearance that are being socially promoted. Public health messages to maintain a healthy body weight, reduce fat consumption, and maintain a healthy lifestyle may also influence adolescent body image perceptions and food management behavior (Centers for Disease Control (CDC), 1992; Read, Harveywebster, \& Usinger-Lesquereux, 1988). Further, motivations for thinness or health may be strengthened or weakened by other variables, such as self-esteem and socioeconomic status (SES) (Lowry, Kann, Collins, \& Kolbe, 1996; Witte, Skinner, \& Caruth, 1991).

In the following sections, the evidence for the existence of cultural messages of thinness and health will be discussed. How these messages affect female adolescent self concepts and health behaviors, and how these concepts and behaviors may be predicted by body image satisfaction, food management behavior, self-esteem, and SES will be examined. 


\section{Desire for Thinness}

\section{Evidence for Cultural Standards of Thinness}

The existence of cultural standards of thinness in our society has been documented by studies of the media and the retail and entertainment industries. The results of these studies indicate that messages of thinness are promoted by or within these industries and that these messages receive considerable exposure in society. Mazur (1986) described how modern industries of advertising, retailing, and entertainment aggressively promoted standards of appearance to women through the media. Collins (1989) reported that $90 \%$ of the consumers of the diet/obesity industry were women. Downs and Harrison (1985) demonstrated that television viewers were confronted with over 5000 attractiveness messages per year, many of which used female performers. Silverstein et al. (1986) found that women received more media messages than did men to be slim and stay in shape. They also found that female models had become significantly less curvaceous and movie actresses had become significantly thinner since 1901 . Guillen and Barr (1994) discovered similar results in their study of changes in female models' measurements in a magazine designed for female adolescents. They found that the models became progressively thinner and more linear between 1970 and 1990.

\section{Evidence for Female Adolescent Susceptibility to Cultural Messages About Appearance}

Adolescent females may be particularly vulnerable to industry and media messages about appearance because appearance has been found to have a major influence on adolescent girls' social acceptance and identity at a time when these factors are dominant needs (Prokhorov et al., 1993). In addition, girls may believe that media images of appearance are realistic goals for themselves because the media blurs the boundaries between fantasy and reality, promoting 
models as realistic representations of people, rather than as the carefully manipulated images they actually are (Freedman, 1984).

Researchers have confirmed the importance of appearance to female adolescents. Prokhorov et al. (1993) found that physical appearance was the most valued characteristic of adolescents and that its value grew over time. Freedman (1984) determined that long before puberty girls learn that beauty is a basic dimension of the feminine gender role. Cultivation of beauty then becomes a major task for females during adolescence. Both Collins (1988) and Searles et al. (1986) described adolescence as a period characterized by increased awareness of self with special focus on weight and appearance. According to both sets of researchers, adolescents are keenly aware of the ways in which their developing bodies may not measure up to cultural ideals.

Shaw and Kemeny (1989) reported that social identity and social acceptance are dominant needs of adolescents, while Adams, Gullotta, and Markstrom-Adams (1994) reported that an attractive appearance increases social value and social acceptance by others. Butters and Cash (1987) and Berscheid, Walster, and Bohrnstedt (1973) found that physical attractiveness significantly influenced female psychosocial experiences and development. Zakin et al. (1984) demonstrated that adolescent girls' self-perceived level of attractiveness significantly affected their popularity and perception of social acceptance.

Since achieving a successful appearance is perceived by female adolescents as being necessary to their survival, female adolescents should strongly prefer a thin body image if they equate thinness with having a successful and desirable appearance. Evidence indicates that this is the case for some female adolescents and young adult women. 


\section{Evidence for Desire for Thinness in Female Adolescents and Young Adults}

Data on body image preferences present the clearest evidence that adolescent females equate thinness with having a successful and desirable appearance. One group of researchers documented this directly: Silverstein, Perdue, Peterson, Vogel, and Fantini (1986 b) found that female adolescents equated thinness with characteristics of intelligence. Guy, Rankin, and Norvell (1980) found thinness to be associated with physical attractiveness and feminine personality traits such as compassion, affection, and understanding. Other researchers have shown that women and girls place more importance on thinness than do males, and in some case place more importance on being thin than on being attractive to males. Fallon and Rozin (1985) found that female college students thought they were significantly heavier than the female ideal while male students did not think themselves heavier than the male ideal. Mable, Balance, and Galgan (1986) found that female college students who believed their weight was greater than the norm exaggerated this discrepancy by $15 \%$ while male students exaggerated by less than $1 \%$. When female students in a later study by Rozin and Fallon (1988) were asked to pick the figure they thought would be most attractive to men, they chose figures significantly thinner than the female figures preferred by male students. Cohn, Adler, Irwin, Millstein, Kegeles, and Stone (1987) demonstrated that $20 \%$ of the adolescent girls they studied chose as ideal figures that were significantly thinner than the figures they thought would be most attractive to boys. Gray (1977), Cash and Green (1986), and Dolan, Birtchnell, and Hubert (1987) discovered that women and adolescent girls who were underweight tended to see their weights and body sizes as normal and satisfactory. Fowler (1989) and Ben-Tovim and Walker (1994) found that overweight women and girls had more body dissatisfaction than did other 
groups of females or males. Hall, Cousins, and Power (1991) and Brodie, Bagley, and Slade

(1994) discovered that girls as young as seven to nine years of age wanted to look thinner than they were and chose as ideal figures that were thinner than their own.

While these findings indicate that desire for thinness is a motivating factor in some girls, they do not apply to all the children, adolescents or young adult women who participated in these studies. There is evidence that some female adolescents and young adult women are influenced by other messages, such as those concerning health.

\section{Desire for Health}

\section{Evidence for Cultural Messages of Health}

Health messages currently promoted in our society originate from several well-publicized reports issued by governmental and health professional organizations. In 1973, the National Research Council and the American Medical Association issued a joint statement recommending that Americans reduce blood cholesterol levels and maintain a desirable body weight through an appropriate combination of physical activity and caloric intake. In 1979, the U.S. Surgeon General issued a report which advocated national commitment and individual involvement in health promotion and disease prevention. Recommendations were made to decrease fat and cholesterol intake, increase intake of fruits, vegetables, and grains, and participate in regular, moderate exercise (Department of Health, Education, and Welfare, 1979).

Since their original formulation, the recommendations have been kept before the public through numerous programs and publications. Magazines, television and radio programs, and books devoted to health and fitness abound (Alonzo, 1993; Cash \& Green, 1986; Glassner, 
1989). In addition, health educators have begun to target children and adolescents for health promotion programs in an effort to prevent future chronic disease in the population (Elias, 1990; Garrison et al.,1996; Miller, Thomson, \& Holcomb, 1988; Perry et al., 1988; Prokhorov et al., 1993). Adolescents may thus be exposed to health messages through general health promotion programs, the media, and school education programs.

Evidence for Desire for Health in Female Adolescents and Young Adults

Some studies indicate that both male and female adolescents are trying to respond to health messages. Radius, Dillman, Becker, Rosenstock, and Horvath (1980) found that $44 \%$ of the adolescents they studied "worried" about their health. Read et al. (1988) showed that adolescents were trying to comply with dietary guidelines and reported that they had the most success with eating a variety of foods and avoiding too much fat. The CDC (1992) found that older adolescents reported consuming significantly less fat than did young adolescents, indicating increasing awareness and motivation as adolescents matured. Frank, Winkleby, Fortmann, Rockhill, and Farquhar (1993) demonstrated that a cholesterol education and reduction program aimed at adults had a significant effect on the knowledge and serum cholesterol levels of twelve to twenty-four year old adolescents and young adults in one city. Torres, Fernandez, and Maceira (1995) determined that a high value of health was significantly correlated to general health behavior, mental health, safety behavior, and good nutritional habits in older adolescents.

Results from a few studies indicate that adolescent females in particular are responding to health messages. Radius et al. (1980) found that more female than male adolescents stated health concerns. Shaw and Kemeny (1989) tried to promote female adolescent fitness in high 
school students by promoting the thin ideal. They found that this approach failed and that they had much better success promoting fitness as healthy, an indication that some adolescents do prefer health over thinness. Prokhorov et al. (1993) demonstrated that their educational program on cardiovascular health and risk factor prevention had a significant effect on exercise and food choices of adolescents, particularly female adolescents. Nichter et al. (1995) discovered that some adolescent girls considered dieting to be an unhealthy food management strategy prone to failure. These girls chose instead to follow a strategy of "watching what they eat" in order to be healthy. Magilvy et al. (1987) found that female adolescents described being healthy as "looking trim and feeling good," and associated health with eating a good diet and exercising. This finding was confirmed by Saltonstall (1993) who noted that when young women were asked what kinds of things they did to be healthy, they listed "practicing good nutrition" first. Men, on the other hand, were found to put nutrition third on their lists.

Other research indicates that adolescents follow less than satisfactory diets and health habits. From a 1989 national adolescent student health survey, Prokhorov et al. (1993) reported that nearly $40 \%$ of adolescents ate fried foods at least four times a week, and $45 \%$ ate three or more snacks a day, over 60\% of which were "junk" foods. The CDC (1992) concluded that $77 \%$ of adolescents did not eat enough fruits and vegetables. They also determined that adolescents consumed more than $30 \%$ of their calories from fat and more than 300 milligrams of cholesterol per day. The International Food Information Council (IFIC) (1993) reported that teenagers were commonly deficient in iron, calcium, and vitamin A. McCaleb and Edgil (1994) found that while adolescents did engage in some self-care practices, they practice lower levels of self-care in the area of nutrition. These results were confirmed by Miller et al. (1988), who 
found that adolescents reported failing to follow through appropriately on health and nutrition behaviors, and by Lawrence and Shank (1993), who found that female college students failed to consume enough fruits and vegetables and over consumed "junk" foods.

In the area of nutrition knowledge and education, female adolescents have also been found to be at risk. Searles et al. (1986) concluded that fewer than $50 \%$ of the fourteen to sixteen year old girls they tested possessed the nutrition knowledge necessary for safe weight loss. Killen et al. (1993) discovered that even after an 18 lesson health education program, female adolescents persisted in pursuing unhealthy eating habits. These results indicate that many female adolescents do not place a high priority on health knowledge and behavior. This implication is supported by Backett and Davison (1995) who found that adolescents and young adults thought it was un-youthful and middle aged to worry about healthy lifestyles and chronic diseases, and that junk food would not hurt them because they would "burn it off."

The research indicates that adolescents are not a homogeneous group with respect to health behavior and concerns. Some value health and good nutrition while others do not. Some value health but equate good health with the culturally sanctioned standard of appearancethinness. Others value thinness but not health. Differences in these motivations and values may be related to differences in self-image and health related behavior. Some of the variables that may predict those differences are examined in the following sections. 


\section{Predictor Variables}

\section{Body Image Satisfaction}

Body image satisfaction is a key issue for female adolescents and the researchers and educators who work with them. Body image is considered to be a complex of body experiences, including the concept(s) and fantasies individuals have about their appearance (Shontz, 1974). Appearance has been shown to be extremely important to females for whom it is much more integrally related to self-concept than it is for males (Franzoi \& Shields, 1984; Secord \& Jourard, 1953; Wooley \& Roll, 1991). Because of this, women and girls associate much of their personal self-esteem and social worth with their physical appearance, judge their bodies on a part by part basis, strive for perfection in every detail of appearance, and express more self criticism about their appearance than do men (Adams et al., 1994; Berscheid et al., 1973; Cash, Winstead, \& Janda, 1986; Clifford, 1971).

Many researchers have documented body image dissatisfaction in female adolescents. The majority of evidence thus far indicates that girls associate body image acceptability with social standards of appearance and body image dissatisfaction with desire for thinness Berscheid et al., 1973; Cash \& Green, 1986; Cohn et al., 1987; Gray, 1977; Fallon \& Rozin, 1988; Fowler, 1989; Mable et al., 1986). Thus, body image dissatisfaction should be a good predictor of desire for thinness.

Body weight has been shown to be a strong indicator of body image by a number of researchers. Mahoney and Finch (1976) and Fowler (1989) demonstrated that for women, weight was the variable most representative of body image. Berscheid et al. (1973) found that the mid-torso area represented body image for many women, and there was a strong correlation 
between the mid torso and body weight. Damhorst et al. (1987) found the same strong correlation between the mid torso area (abdomen and waist) and weight in adolescent girls. Thus, body weight satisfaction should be a good predictor of body image satisfaction.

Body image dissatisfaction has been shown to be strongly correlated to unhealthy food management behaviors such as chronic dieting and eating disorders (Collins, 1989; Damhorst et al.,1987; Killen et al., 1993; Moreno, 1995;). There is widespread evidence that girls who experience body image dissatisfaction turn to dieting to achieve a more satisfactory body image. Dwyer, Feldman, Seltzer, and Mayer (1969) were among the first researchers to report that female adolescents were dieting for the sake of appearance. Searles et al. (1986) stated that body image dissatisfaction was the primary reason for adolescent dieting. Greenfield, Quinlan, Harding, Glass, and Bliss (1987) found a high frequency of body image concerns and dieting behaviors among female adolescents. French, Story, Downes, Resnick, and Blum (1995) discovered that diet frequency was correlated to body image: the more frequent the dieting, the poorer the body image. These results suggest that girls who are strongly influenced by cultural standards of thinness may experience body image dissatisfaction which in turn may lead them to indulge in unhealthy food management behaviors.

One factor that could modify the ability of body image dissatisfaction to predict chronic dieters may be derived from adolescent egocentrism and female perfectionism (Adams et al., 1994). These characteristics may make female adolescents consider a weight gain of several pounds over their preferred weight significant enough to report as grounds for body image/body weight dissatisfaction. These differences, no matter how small, do represent body dissatisfaction but may not be extreme enough to stimulate unhealthy food management behaviors. 
Although the evidence is preliminary, several researchers have found that some adolescents and young adult women associate body image and appearance with health. Magilvy et al. (1987) and Saltonstall (1993) found that being thin was associated with being healthy by the young women they interviewed. This may be additional evidence that public health messages to maintain a healthy weight are having an impact on young people's standards of physical appearance, even if their dietary habits are lagging behind. Nichter et al. (1995) pointed out that most of the researchers of adolescents' health attitudes and behaviors have paid more attention to negative rather than positive motivations and behaviors. To obtain a more complete picture, other variables that may motivate body image attitudes and related behaviors, such as desire for health, need to be explored.

Weight perception accuracy

As already mentioned, studies on body image perceptions have yielded some of the strongest evidence regarding preferences for thinness. Gray (1977) and Cash and Green (1986) found that girls who were underweight tended to see their weights and sizes as normal and satisfactory, thus allowing themselves to experience body image satisfaction. Gray (1977) also found that overweight men and women tended to underestimate their weights, while Fowler (1989) found that overweight women had more body image dissatisfaction than any other group of males or females. Gray's results strengthen the premise that some people attempt to arrive at body image satisfaction through weight perception adjustments. Fowler's results suggest that others are unable to make the perception adjustment and so remain extremely dissatisfied with their body images. Thus, weight perception seems to be the first step involved in defining body image satisfaction or dissatisfaction and should be a good indicator of prevailing standards of 
body image. Since thinness is a prevailing body image standard, weight perception should be a good predictor of girls who desire thinness.

Overall, the research indicates that body image variables should be good predictors of desire for thinness and dieting behavior in adolescent females. They may also predict desire for health.

\section{Self-esteem}

Self-esteem has been shown to be integrally related to body image and body weight. Harter (1988), Wendel and Lester (1988) and Martin, Housley, and McCoy (1988) demonstrated that adolescent self concept was strongly correlated to physical attractiveness. Berscheid et al. (1973) determined that body image factors were strongly correlated to selfesteem and that teens who considered themselves unattractive were the unhappiest group of respondents they surveyed.

Physical attractiveness has been shown to have both sexual and social dimensions. Franzoi and Shields (1984) found that the body parts women most strongly associated with selfesteem were not considered integral parts of sexual attractiveness. Cohn et al. (1987), and Fallon and Rozin (1988) found that girls preferred body images thinner than the ones they thought would be most attractive to males, thus indicating that sexual attractiveness was secondary to ideal body image. Ben-Tovim and Walker (1994) found that all subjects disparaged their bodies, though all but the very heaviest women felt attractive. Dawson (1988) found that women's perceptions of appropriate body weight were most strongly influenced by the weights of their peers. Thus, body image satisfaction seems to derive more from the social rather than the sexual definition of body image, and self-esteem is strongly correlated to this 
dimension.

Self-esteem has been strongly correlated to positive health behaviors in adolescents and adults. It has been shown to reduce susceptibility to social and environmental pressures and influences and to increase perceptions of self-efficacy (belief in one's competence and ability to cope). People with greater self-efficacy may develop positive health habits (Torres et al., 1995). This suggests that high self-esteem may predict girls who value health and are better at resisting cultural pressures for thinness. Torres et al. (1995) showed that both value of health and selfesteem significantly predicted adolescent health behavior. Dielman, Leech, Lorenger, and Horvath (1984) demonstrated that young adolescents with high self-esteem tended to practice fewer health-risk behaviors, while Fisher, Schneider, Pegler, and Napolitano (1991) and French et al. (1995) demonstrated that female adolescents with low self-esteem indulged in clusters of health risk behaviors.

Self-esteem has also been correlated to food management behavior. Newell, Hammig, Jurich, and Johnson (1990) found that self-esteem positively influenced diet quality and number of meals eaten per day by adolescent females. Witte et al. (1991) found that self-concept variables were positively correlated to patterns of healthy nutrient intake.

Because of its relationship with body image, health behavior, and diet, high self-esteem may predict body image satisfaction, desire for health, and positive food management behavior. Low self-esteem may predict desire for thinness and unhealthy food management behavior. 


\section{$\underline{\text { Socioeconomic Status (SES) }}$}

SES is a composite measure that typically incorporates economic status (measured by income), social status (measured by education), and work status (measured by occupation) (Adler, Boyce, Chesney, Cohen, Folkman, Kahn, et al., 1994). SES has been linked to health throughout history. Individuals higher in the social hierarchy have been found to enjoy better health than do those lower in the hierarchy (Adler et al., 1994; Blane, 1995).

These differences may be due in part to differences in health knowledge and behaviors. Davis, Winkleby, and Farquhar (1995) surveyed cardiovascular risk reducing knowledge in two northern California cities between 1980 and 1990 and determined that significant initial differences in cardiovascular health knowledge widened over the ten year period between people of lower and higher SES. Frank et al. (1993) found improvements in nutrition knowledge of adults who were targeted for plasma cholesterol reduction, but cholesterol levels improved only in the higher SES population. Davis et al. (1995) documented significant differences in nutrition knowledge between people of higher and lower SES: the lower the SES, the less knowledge the consumer had. Searles et al. (1986) found that adolescent girls' nutrition knowledge scores were positively correlated to their mothers' education and income levels.

Several researchers have reported a relationship between SES variables and food management behaviors. Lowry et al. (1996) demonstrated that as the responsible parent's educational level increased, adolescent smoking, sedentariness, and insufficient consumption of fruits and vegetables decreased. Among adolescent girls but not boys, they found that consumption of high fat foods decreased with increasing parental educational level. Goldblatt, Moore, and Stunkard (1965) and Jeffery and French (1996) discovered a strong correlation 
between lower SES and higher incidence of obesity.

Other variables may modify the predictive strength of SES factors. Factors such as culture, church attendance, race, and peer groups have been shown to influence self-care practices, which can include health practices. McCaleb \& Edgil (1994) reported a significant positive correlation between religiosity and health practices. A study by Diehr, Koepsell, Cheadle, Psaty, Wagner, and Curry (1993) demonstrated a relationship between local culture and health related behaviors. Even after variables such as SES were controlled, significant differences across communities with respect to health behaviors such as smoking, alcohol consumption, and consumption of fat remained.

Researchers have attempted to link self-esteem to SES but have arrived at conflicting results. Barnes and Farrier (1985) studied the stability of self-concept in low income rural and urban black and white children from Appalachia and the South. They found self-concepts to be relatively stable over the ten-year period studied, and that girls had lower self-concepts than boys did. Ho, Lempers, and Clark-Lempers (1995), on the other hand, found that family economic hardship had an adverse effect on adolescent self-esteem. Mullis, Mullis, and Normandin (1992) found that self-esteem was significantly correlated to only one SES factor: family income. Perhaps the influence of local culture and religiosity may explain some of these different results.

The relationships between SES variables and desire for thinness and related variables such as body image dissatisfaction have not been well explored. Jeffery and French (1996) found that women of low SES were more likely to use unhealthy weight loss practices and experience less social support for healthy eating and exercise than were those of high SES. This could indicate 
that female adolescents of low SES might be more likely to indulge in unhealthy food management behaviors such as crash or chronic dieting if they desired thinness. Since low SES is associated with fewer positive health practices and less health knowledge (Frank et al., 1995: Jeffery \& French, 1996; Lowry et al.,1996), it is more likely that unhealthy weight loss behavior among low SES female adolescents would be motivated by desire for thinness.

The correlations between SES and health status, knowledge, and behaviors, suggest that high SES should be a good predictor of desire for health and healthy food management behaviors. The relationships between SES and self-esteem, and SES and desire for thinness bear further examination. In West Virginia, where low SES and obesity are common (West Virginia Vital Statistics, 1996) and religious and cultural influences may be strong, exploration of these relationships may be of particular value.

\section{Food Management Behavior}

Adolescent food management behavior has been the focus of concern for many researchers and health care educators. Adolescents have been shown to follow poor quality diets high in sugar and fat and low in fruits and vegetables (CDC, 1992; IFIC, 1993; Lawrence \& Shank, 1993). Female adolescents have been shown to be overly concerned with weight and to indulge in potentially unhealthy food management behaviors such as crash dieting, bingeing, and purging (Cash et al., 1986; Killen et al., 1993; Moreno, 1995). In addition, eating disorders have been shown to be most prevalent among female adolescents and young adult women (Cash \& Green, 1986; Cash et al., 1986; Killen et al.,1994; Wooley \& Roll, 1991). Many authors have reported weight loss behavior in girls who wished to be thinner despite already being within normal weight for height ranges. Shaw and Kemeny (1989) and 
Littrell, Damhorst, and Littrell (1990) reported that a substantial number of girls of normal weights reported engaging in restrictive eating behavior because they desired weight loss. Storz and Greene (1983) found that adolescent girls who wished to lose more than $10 \%$ of their current weight found fad diets more desirable than did girls who desired weight loss of less than $10 \%$ of body weight.

As already mentioned, Rozin and Fallon (1988) found that women, but not men, showed high levels of weight concern and diet behavior. Newell et al. (1990) reported that girls with the poorest diets (those who skipped meals frequently and had a history of frequent dieting) perceived themselves to be larger than girls with good diets, suggesting that concepts of physical appearance and thinness may affect food intake. Serdula et al. (1993) analyzed data from the 1991Youth Risk Behavior Survey that included over 60,000 adults and over 11,000 high school students. They determined that $44 \%$ of female high school students wanted to lose weight, and roughly half of these students had reported skipping at least one meal to do so. Only $15 \%$ of the male students reported wanting to lose weight. All these studies indicate a strong correlation between dieting and desire for thinness.

Desire for health has not been well studied as a motivation for food management behavior. Only one group of researchers, Nichter et al. (1995), has looked at female adolescent food management behavior in connection with desire for health. Their results support the premise that some adolescents use food management behaviors to respond to health concerns. They found that adolescent girls divided the term "dieting" into several different food management behaviors. These included "watching what they ate," a strategy that involved modifying the kind of food rather than the quantity eaten, "dieting/watching," a combination of 
occasional dieting and "watching," and dieting.

Girls who defined themselves as "watchers" perceived dieting as a difficult food management strategy that was prone to failure. "Watching" was described as a positive behavior at which girls could succeed. It consisted of avoiding "junk" and fatty foods and eating more fruits and vegetables. Thirty-six percent of the population Nichter et al. studied described themselves as "watchers." Sixty percent of this sub-population stated that they followed this food management behavior specifically for health reasons. The remaining $23 \%$ "watched" to maintain their weight, and 12\% "watched" to lose weight. Of the sub-group of watcher/dieters in this study, $30 \%$ described their food management behavior as being motivated by health and $41 \%$ reported weight loss as their motivation. Thirty percent of girls who described themselves as dieters stated that they were motivated by health while $74 \%$ of dieters stated that they were motivated by weight loss. Dieters constituted a very small sample size relative to the other groups in the study, so these percentages may not accurately reflect the incidence of diet motivations in the larger female adolescent population. The results do suggest, however, that desire for health is a motivation for some girls who diet and/or who watch what they eat.

There may be evidence from other researchers that populations of girls who diet and "watch" or just "watch" may exist. Davies and Furnham (1986) found that a significant number of 12 and 18 year old girls had considered altering the kind of food they ate as well as the amount of food they ate in order to alter their weight. These girls may have been what Nichter et al. described as "dieter-watchers." Serdula et al. (1993) found that $26 \%$ of female high school students reported trying not to gain weight, a motivation described by some of the "watchers" in the study done by Nichter et al. (1995). Saltonstall (1993) found that the young women she 
interviewed placed equal importance on the caloric and nutrient content of foods. Concern about the nutrient content of foods suggests a concern about the health impact of foods. Thus, these findings may also support the premise that food management behavior is linked to desire for health.

An overlooked point in the research on food management behavior in adolescents is the trend toward less exercise and more consumption of "junk" and fast foods (Backett \& Davison, 1995; CDC, 1994; Lawrence \& Shank, 1993; Read et al., 1988; Shaw \& Kemeny, 1989). Consumption of fast foods, which are generally high in fat and calories, coupled with physical inactivity, may well lead to concerns about weight and diet for some adolescents. These concerns may indicate a healthy response to the sedentary and fast food cultures, rather than an unhealthy response to cultural pressures for thinness.

Several other phenomena may contribute to the high numbers of girls who report dieting. During a previous study by Nichter et al. (1994), some adolescent girls explained that they sometimes reported feeling fat and dieting when neither was true, in order to conform to social pressures. In their 1995 study of dieting and "watching" behaviors, Nichter et al. confirmed these results. They tracked actual dietary intakes of girls, using food records, phone interviews, and direct observations in order to match actual food management behaviors with reported food management behaviors. They discovered that only $9 \%$ of the girls' food records were designated as dieting days on days when $44 \%$ of girls claimed to have been dieting. Thus, among self-labeled dieters, there was only a small group of girls who actually did diet (restricted food intake) when they said they were doing so. An additional factor that may interfere with determining the actual number of girls who diet is the term itself. "Dieting" may 
be a catchall word for any kind of attention paid to food because other terms do not exist. Therefore, some girls may describe themselves as "dieting" when in fact they are "watching." (Nichter et al., 1995). These factors suggest that the incidence of "real" dieting, reported in the literature as being as high as $77 \%$ in some cases, may be overstated.

The evidence suggests that food management behavior may be related to both desire for thinness and desire for health. "Watching" may be a good predictor of desire for health. Dieting and dieting/watching may predict either desire for thinness or health. 


\section{Summary}

Evidence for both desire for thinness and desire for health exists in the female adolescent population. While the predominance of evidence suggests that desire for thinness is the dominant motivation, few researchers have looked for evidence of desire for health in female adolescents. Additional exploration of these motivations and related factors is needed.

Variables that may predict desire for thinness and health include body image satisfaction, weight perception accuracy, food management behavior, self-esteem, and SES. Body image satisfaction has been shown to be strongly correlated to self-esteem, and self-esteem to positive health habits and positive food management behaviors. Body weight dissatisfaction and low selfesteem have been correlated to desire for thinness and health risk behaviors. Thus body weight satisfaction and high self-esteem should be good predictors of desire for health and healthy food management behaviors, while body weight dissatisfaction and low self-esteem should be good predictors of desire for thinness and unhealthy food management behaviors. Weight perception accuracy has been associated with desire for thinness in some adolescents and young adults and may be a good indicator of this motivation. Food management behavior has been shown to include dieting, "watching," and a combination of the two. These behaviors merit further study to determine their ability to predict desire for thinness and/or desire for health in adolescent females. SES variables such as parents' education and family income have been shown to be correlated to health status, behavior, and knowledge, but not directly to desire for health. The demographic variable of religiosity has also been shown to be related to health behavior. These factors merit further study to determine their ability to predict desire for health in female adolescents. 


\section{MATERIALS AND METHODS}

\section{Overview}

A survey questionnaire (Appendix A) was administered to eighteen and nineteen yearold females in north-central West Virginia in order to determine the incidence of desire for thinness and health within this population. Data were also collected on body image motivations, SES, self-esteem, and food management behaviors so that variables derived from these factors could be tested for their ability to predict girls who desired thinness or health. Other statistical relationships among variables were also examined, and descriptive frequencies were tabulated where appropriate.

\section{Procedures}

\section{Questionnaire}

In addition to original questions, questions used by Nichter et al. (1995) and the ten question Rosenberg Self-Esteem Inventory (Rosenberg, 1965) were included in the questionnaire. The questionnaire was critiqued by graduate students in nutrition and then pilot tested and critiqued by several female adolescents. After all suggestions were incorporated, the questionnaire was pilot tested again by thirty students in two general nutrition classes.

\section{$\underline{\text { Subjects }}$}

A convenience sample of eighteen and nineteen year old female adolescents currently living in the north-central West Virginia region was sought at the following locations: Davis and Elkins College, Fairmont State College, Wheeling Jesuit University, West Virginia University, 
Salem-Teikyo University, and United Technical Center (from where questionnaires were received from girls who attended Lincoln High School, Bridgeport High School, Robert C. Byrd High School, Doddridge High School, and Liberty High School). Experimental Design

Using the statistical procedure of discriminate analysis, the following groups of predictor (independent) variables were tested to determine whether they were significant in the prediction of assignment of one dependent (grouping) variable:

1. Body image

2. Self-esteem

3. Socioeconomic status

4. Food management behavior

Female adolescents were divided into four levels of one dependent or grouping variable:

I. Those who desired thinness for the sake of appearance.

II. Those who desired health, not thinness.

III. Those who desired both thinness and health.

IV. Those who desired neither thinness nor health. 


\section{Independent (Predictor) Variables}

The following section explains processing and coding of predictor variables. In addition, a coded questionnaire is included in Appendix B.

\section{Body Image Variables}

Body Weight Satisfaction. Answers to questions \#12 and 13 were used to determine body weight satisfaction.

Question \# 12. Current Weight

Height

Question \# 13. Are you satisfied with your current weight?

2 Yes, I am satisfied. $\underline{1}$ No, I would prefer to weigh pounds. $\underline{0}$ Don't know/have no opinion.

Weight Perception Accuracy Score. Answers to questions \#12 and 17 were used to determine the values of this variable. Actual body mass index $(B M I)$ values $(B M I=$ weight in kilograms. $\div$ height $^{2}$ in meters), obtained from answers to question $\# 12$, were converted to the same scale found in question \#17.

Question \# 17. Please select one answer. How would you describe yourself at your current weight or size?
a. 1 heavy
b. 2 on the heavy side of average
c. 3 average
d. 4 on the thin side of average
e. 5 thin
f. 0 don't know

The following conversions were made according to values and ranges described by Beumont, Al-Alami, and Jouyz (1988) and Whitney and Rolfes (1994): BMIs of 16 to $18.9=$ thin, 19 to $20.3=$ thinner than average, 20.4 to $22.9=$ average, 23 to $25.9=$ heavier than 
average, 26 or more $=$ heavy. These discrete categories of converted BMI values were used to evaluate how accurately subjects compared their weight and size to the weights and sizes of other women. Subjects' perceptions were classified as accurate estimates, underestimates, or overestimates.

\section{$\underline{\text { Self-esteem variable }}$}

Self-esteem group. Answers to question \#32 were used to determine self-esteem groups. This question is an adaptation of the Rosenberg Self-esteem Inventory (Rosenberg, 1965). For purposes of consistency with the rest of the questionnaire, the four point Likert scale was reversed so that "strongly disagree" $=1$, "disagree" $=2$, "agree" $=3$, and "strongly agree" $=4$. The ten questions were divided into categories of positive and negative statement categories. Answers that disagreed with negative statements were transformed so that high scores indicated positive responses. 
Question \# 32. Using the following scale, please write the number that best describes your feelings about yourself on the line next to each question.

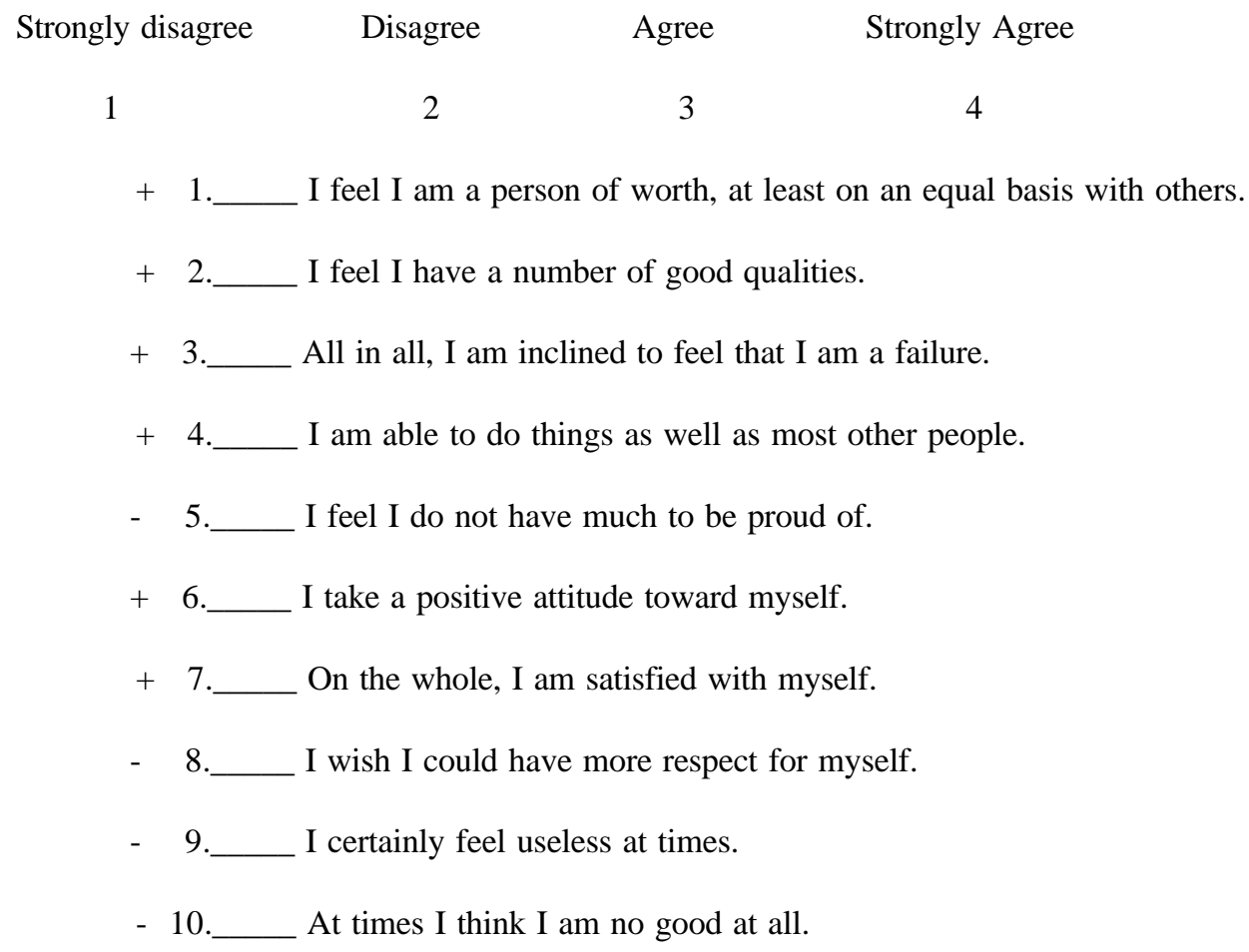

For purposes of analysis, scores were converted into discrete categories, as follows: score of 14-19, score of 20-24, score of 25-29, score of 30-34, score of 35-40.

\section{$\underline{\text { Socioeconomic and demographic variables }}$}

Family income group. Answers to question \#8 determined categories of family income.

Question \# 8. Your family's average income per year: please put a check by the correct selection. If you are not certain, please make your best guess : $\underline{1}$ under $\$ 10,000 \quad \underline{2} \$ 10,000-19,000$

$$
\underline{3} \$ 20,000-29,000 \underline{4} \$ 30,000-39,000 \quad \underline{5} \$ 40,000-49,000 \quad \underline{6} \$ 50,000-59,000 \quad \underline{7} \$ 60,000 \text { or more }
$$

Mother's education group. Answers to question \#9 determined the highest level of education achieved by subjects' mothers. 
Question \# 9. Highest grade completed by mother: 1 less than $12^{\text {th }}$ grade

$\underline{2}$ high school graduate $\quad \underline{3} 1$ or more years vocational school $\underline{4}$ vocational school graduate

$\underline{5}$ one or more yrs college $\quad \underline{6}$ college graduate $\quad \underline{7} 1$ or more years postgraduate school

Father's education group. Answers to question \#10 were converted to the same categories described under mother's education group.

Religiosity. Answers to question \#11 were used to determine religiosity.

Question \# 11. Are you an active member of a church, temple, or religious group?

$\underline{2}$ Yes $\underline{1}$ No

\section{$\underline{\text { Food management variables }}$}

Food Management Group. Answers to question \#22 were used to classify girls into four food management groups, according to the categories defined by Nichter et al. (1995). These categories were: dieters, "dieter/watchers," "watchers," and "neithers."

Question \# 22. Please select one of the following choices: Would you describe yourself as someone who

a. 1 Diets (restricts food intake regularly or occasionally) dieter

b. 2 Uses a combination of dieting and watching what you eat dieter/watcher

c. 3 Watches what you eat (does not diet) watcher

d. 4 Neither diets nor watches what you eat FMG-neither

To avoid confusion between comparison group IV (girls who neither desired thinness nor health) and food management "neithers" (girls who neither dieted nor watched what they ate), food management "neithers" will be referred to hereafter as "FMG-neithers." The term "watching" will be used hereafter to refer to girls who "watch what they eat." 


\section{Dependent Variable}

Subjects were assigned to four comparison (dependent variable) groups based on their answers to questions \# 12, 13, and 30 .

Question \# 12. Current Weight

Height

Question \# 13. Are you satisfied with your current weight?

Yes, I am satisfied. ___ No, I would prefer to weigh pounds. ___ Don't know/have no opinion.

Question \# 30. Please check all the following statements about health, diet, and lifestyle that apply to you:

__a. I am actively involved in following a healthy diet and lifestyle because health is important to me.

__b. I think it is a good idea to follow a healthy diet and lifestyle, but it's not a priority for me (I don't go out of my way to do it).

__c. I don't think that following a healthy diet and lifestyle would make an important difference in my health.

___. I am trying to do a better job of following a healthy diet and lifestyle because I do think health is important.

__e. I don't know much, or I don't think much about my health or my diet and lifestyle.

__f. It isn't important to me to follow a healthy diet and lifestyle right now, but it probably will be when I'm older.

Answers to questions \# 12 and 13 were used to make the first division between girls who desired thinness and those who did not. Self-reported heights, weights, and preferred weights were converted to actual and preferred BMI values. Several groups of researchers have used BMI values to determine perceptions and desire for thinness in young females (Sciacca, Melby, Hyner, Brown, \& Femea, 1991; Silverstein et al., 1986). For adolescent and young adult women, Whitney and Rolfes (1994) stated that normal BMI values were between 19 and 24, with 22 considered average. Beumont et al. (1988) reported an average range of BMI values of 
20.4 to 21.3 for girls. Combining these values yielded an average range of 20.4 to 22.9. Girls who desired BMIs of less than 20.4 or who were satisfied with BMIs of less than 20.4 desired figures that were thinner than average and were considered to desire thinness. Girls who were satisfied with or who desired BMIs of 20.4 or greater were considered not to desire thinness.

Based on answers to question \#30, girls who did and did not desire thinness were further subdivided into those who did and did not desire health. Girls who chose \# 30a (active involvement with healthy lifestyle) and/or 30d (trying to do a better job of following a healthy lifestyle), were considered to desire health, while girls who choose \#30b (healthy lifestyle is not a priority), or 30f (healthy lifestyle not important right now) were considered not to desire health. If either \#30c (following a healthy lifestyle does not make a difference in my health) or \#30e (don't know or think much about health or lifestyle) was selected alone, the subject was considered not to desire health. If \#30c or 30e were chosen in combination with \#30a or \#30d, the subject was considered to desire health. Girls who chose \#30b in combination with any other choices were considered not to desire health.

Based on these criteria, girls were assigned to the four comparison groups as follows:

Group I (desiring thinness): girls who desired BMIs $\leq 20.4$ and who chose \#30b alone or in combination with other choices, or chose \#30c, e, f.

Group II (desiring health): girls who desired BMIs $\geq 20.4$ and who chose \#30a, d, ad, acd, or ade.

Group III (desiring both thinness and health): girls who desired BMIs $<20.4$ and who chose \#30a, d, ad, acd, or ade..

Group IV (desiring neither thinness nor health): girls who desired BMIs $\geq 20.4$ and 
who chose \#30b alone or in combination with other choices, or chose \#30c, e, f.

\section{Additional Statistical and Descriptive Data}

In addition to discriminate analysis, ANOVA was used to determine relationships among variables. Descriptive data were collected on body image motivations, and food management practices and motivations. The additional variables that were used to collect these data are described next.

Body image variables

Body Image Group. Answers to question \#16 were used to assess motivations for body image preferences.

Question \# 16. Why do you feel it is important to be at your preferred weight or size?

You may select one or more answers. If you select more than one, please rank your answers in order of importance $(1=$ most important $2=$ next most important, $3=$ less important, $4=$ least important $)$.

a. to look and feel more attractive to yourself or others

b. to be better liked and accepted by other people

c. to be healthy (having enough energy and being free from illness)

d. to be in good physical shape (having endurance and strength)

Other reason (please explain and rank importance):

Answer \#16a and b describe motivations related to appearance, while \#16c and d describe motivations related to health. To make the most positive response the highest value, ranking values were reversed. Only choices ranked most important (converted rank=4) or next most important (converted rank=3) were used to determine body image group. Choices that were not selected or not ranked were denoted by a " 0 ." Using these criteria, scores for this variable were generated as follows:

$1=$ those who chose only appearance factors as important 
$2=$ those who chose only health as important

$3=$ those who chose a mix of appearance and health factors as important

$4=$ those who chose no factors because body image is not important. (This latter category of girls selected scores of " 1 ," " 2 ," or " 3 " in question \#15, indicating that achieving or maintaining a particular body weight or size was unimportant to them).

Importance Score. Answers to question \#15 were used to obtain scores that described the importance of having or achieving preferred body weights and/or sizes.

Question \# 15. How important is it to you to be at your preferred weight and/or size?

Please circle the number that best describes your answer:

very unimportant unimportant no opinion important very important

$\begin{array}{lllll}1 & 2 & 3 & 4\end{array}$

Weight Loss Group. Answers to questions \#12 and 13 were used to determine the amount of weight loss and gain desired by subjects. Desired amounts of weight loss were assigned to the following categories: no weight loss desired, desired loss of 1 to $3 \mathrm{lb}$., 4 to 6 lb., 7 to $10 \mathrm{lb}$, 11 to $14 \mathrm{lb}$., 15 to $20 \mathrm{lb}, 21$ or more lb.

Size satisfaction Score. In question \#14, discrepancies between girls' actual and preferred pants sizes were determined.

Question \# 14. Are you satisfied with your current pants size?

2 Yes, I am satisfied with my size.

1 No, I would prefer to be: __ smaller__ _ larger by _ـ 1 size _ـ 2 sizes _ 3 sizes or more

$\underline{0}$ Don't know/ No opinion 
Size Loss Group. Answers to questions \#14 were used to determine the values of this variable. Girls were assigned to a size loss group depending on the number of sizes they wanted to gain or lose. Desired size loss categories were defined as follows: 1 size, 2 sizes, 3 or more sizes.

\section{Demographic variables}

Age: Answers to question \#1 determined age. Girls were denoted as either eighteen or nineteen year of age.

Residency. Answers to question \# 4 were used to determine West Virginia residency.

Question \# 4. How many years of junior and senior high school $\left(7^{\text {th }}\right.$ to $12^{\text {th }}$ grades $)$ did you attend in West Virginia schools? years.

Subjects reported the number of years of junior and senior high school they attended in West Virginia. Participants were considered West Virginia residents if they attended at least four years of school in-state.

Race. Answers to question \#5 were used to determine racial categories.

Question \# 5. Please check as many as apply: 1 white $\quad 2$ black $\quad 3$ Hispanic $\quad 4$ Asian

5 Native American 6 Other $\quad(\underline{7=}$ mixed $)$

Racial categories were defined as follows: white, black, Hispanic, Asian, Native American, other, mixed racial background. Participants reporting more than one racial background were assigned to this last category.

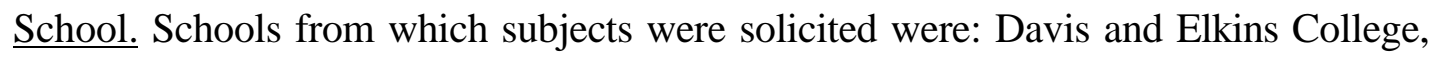
Fairmont State College, Wheeling Jesuit University, West Virginia University, Salem-Teikyo 
University, and United Technical Center (from where questionnaires were received from girls who attended Lincoln High School, Bridgeport High School, Robert C. Byrd High School, Doddridge High School, and Liberty High School).

\section{Food management behavior}

Diet Behaviors. In question \#25, sixteen specific dieting practices were listed, based on practices described by Nichter et al. (1995), Storz and Greene (1983), and local adolescents who pilot tested the questionnaire. Girls were asked to check as many of these practices as they usually used when dieting.

Question \# 25. Please check all the dieting strategies that you usually use or prefer to use when you diet:

___ eat foods with fewer calories

____ eat more fruit and vegetables

_____. eat regular balanced meals

d. eat fewer meals

e. skip meals when hungry

f. fast (stop eating for 1 day or more)

_____ g. go on a weight watcher type diet plan

h. use water pills, laxatives, or diet pills i. go on a crash diet

j. avoid junk food

__

1. cut out snacking

m. intentionally vomit after meals

n. go on an all liquid diet

o. exercise regularly

p. exercise intensively

A "yes" answer was entered if a strategy was checked, and a "no" answer was entered if a strategy was skipped. Strategies were then divided into healthy and unhealthy categories according to those described by Storz and Greene (1983) and Whitney and Rolfes (1993): \#25a, $\mathrm{b}, \mathrm{c}, \mathrm{g}, \mathrm{j}, \mathrm{k}, 1$, and o were considered healthy strategies, and \#25d, e, f, h, i, m, and $\mathrm{n}$ were considered unhealthy strategies. 
Watching Behaviors. Based on specific practices described by Nichter et al. (1995), eight strategies that may have been used by girls who watched what they ate were listed in question \#28. All "watching" strategies were healthy behaviors, so they were not divided into the categories described under dieting behaviors. A "yes" answer was entered if a strategy was checked, and a "no" answer was entered if a strategy is skipped.

Question \# 28. Please check all the strategies that you usually use or prefer to use when you watch what you eat:

____a. eat more fruit and vegetables

b. avoid junk food

c. eat regularly balanced meals

d. eat lower calorie foods e. eat lower fat foods

f. eat the same but notice

g. cut out snacks

h. exercise regularly

Dieting/Watching Motivations: In questions \#24 and 27, motivations for dieting and watching were solicited.

Questions \# 24 and 27. Why do you usually diet/watch what you eat? You may select one or more answers. If you select more than one, please rank your answers in order of importance

(1= most important, $2=$ next most important, $3=$ less important, $4=$ least important).

a. lose weight

b. gain weight

c. maintain your weight

d. maintain or improve your health

To make the most positive response the highest value, ranking values were reversed. Only choices ranked most important (converted rank=4) or next most important (converted rank=3) were used to determine food management motivations. Choices that were not selected or not ranked were denoted by a "0." 
Diet/Watching Frequencies. In questions \#23 and 26, girls were asked to report how frequently they dieted or watched. This variable was coded two different ways: first, using a scale from rarely to always, and second, converting answers to numbers of days per month.

Question \# 26. Please choose the best answer: How often do you watch what you eat ?

$\underline{0.25}$ one to 3 times a yr (rarely ) $\underline{2}$ once or twice a month (occasionally)

$\underline{4}$ once or twice a week (frequently) $\underline{30}$ every day (always)

Junk Food Frequency Score: Answers to question \#18 were used to determine usual intake of "junk" foods.

Question \# 18. How often do you eat fast foods or "junk" foods?

$\underline{0}$ never 1 rarely $\underline{2}$ occasionally $\quad 3$ frequently $\underline{4}$ all the time _ don't know

Exercise Frequency Score. Answers to question \#20 were used to determine frequency of exercise. This variable was coded two different ways: first, using a scale similar to the one for junk food frequency, ranging from never to always, and second, converting answers to number of days per month.

Question \# 20. How frequently do you exercise, or participate in sports or physical activities? (walking, gardening, etc)

$\underline{0}$ less than once a month (never) $\underline{1}$ once a month (rarely) $\quad \underline{4}$ once every 1 or 2 weeks (occas.)

$\underline{10}$ two to 3 times a week (frequently) $\underline{30}$ every day (always) 


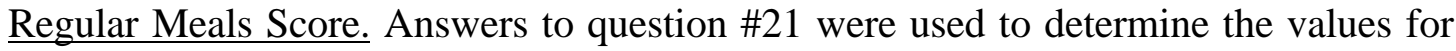
this variable.

Question \# 21. How frequently do you eat regular, nutritionally balanced meals?

$\underline{0}$ never $\quad \underline{1}$ rarely $\underline{2}$ occasionally $\underline{3}$ frequently $\underline{4}$ all the time _ don't know If a girl checked "don't know," the answer was left blank. 


\section{RESULTS}

\section{Demographic Information}

Three hundred forty-five questionnaires were collected from eighteen and nineteen yearold female adolescents. The distribution of some of the demographic variables in the sample population are found in Table 1.

The majority of girls were West Virginia residents, college students, and white. There was an almost even division between girls who were and who were not religious.

\section{Discriminant Analysis}

\section{Comparison Groups}

The number of girls assigned to each comparison or dependent variable group is shown in Table 2. Both desire for thinness and desire for health were found to exist in this sample of female adolescents. Distribution across the four comparison groups was fairly even, with no group having significantly more girls in it than any other group. Twenty-eight percent of girls were assigned to comparison group I, which included girls who desired only thinness, and $23 \%$ of girls were assigned to comparison group II, which included girls who desired health. A group of girls who desired both thinness and health (22\%) and a group who desired neither thinness nor health $(26 \%)$ were also identified.

Predictor Variables

Discriminate analysis of the four comparison groups was performed using different combinations of predictor variables (body image, food management behavior, SES, and selfesteem). In every combination tested, at least one variable from each predictor group was included. 
TABLE 1. Total number, educational level, residency, and racial make-up of subjects in the sample population

\begin{tabular}{lclr}
\hline Variable & $\mathrm{n}$ & Variable & $\mathrm{n}$ \\
& & Race & \\
Total \# subjects & 345 & white & 323 \\
Education & & black & 11 \\
college students & 319 & Asian & 4 \\
high school student & 26 & other & 7 \\
Residency & & Religiosity & \\
W. Va. Residents & 203 & religious & 172 \\
non-residents & 142 & non religious & 168 \\
\hline
\end{tabular}

TABLE 2. Number of subjects assigned to the four comparison or dependent variable groups

\begin{tabular}{lcc}
\hline Comparison Group & $\mathrm{n}$ & $\%$ of total \\
\hline Group I (desiring thinness) & 95 & $28 \%$ \\
Group II (desiring health) & 79 & $23 \%$ \\
Group III (desiring both thinness and health) & 76 & $22 \%$ \\
Group IV (desiring neither thinness nor health) & 90 & $26 \%$ \\
Overall & 340 & $99 \%$ \\
\hline
\end{tabular}


The combination of variables that yielded the highest rate of discrimination or classification among the four comparison groups included the following variables: father's education, religiosity, weight perception accuracy, food management group, and self-esteem group. Although father's education and self-esteem were included in the final model, their contributions were statistically insignificant (Table 3).

\section{$\underline{\text { Discriminate Analysis Results }}$}

General Results. Classification rates obtained using standard stepwise analysis (all variables simultaneously entered into the model) and forward stepwise analysis (variables entered in order of highest discriminatory contribution) ranged from $40 \%$ to $52.6 \%$. Forward stepwise analysis weights the first variable's statistical contribution to the analysis and measures contributions from subsequent variables in relation to the first variable. Standard stepwise analysis was chosen over forward stepwise analysis because it allowed determination of the strongest predictors from an equally weighted mix of variables.

The final predictor model, using standard stepwise analysis, correctly predicted $51.6 \%$ of girls in comparison groups, as shown in Table 4. It accurately classified 64\% of group I (desiring thinness), $49 \%$ of group II (desiring health), 44\% of group III (desiring both thinness and health), and $48 \%$ of group IV (desiring neither thinness nor health). Since the chance probability of correctly predicting four dependent variable groups was $25 \%$, discriminate analysis added only an additional $26.6 \%$ probability of accuracy to prediction. (Forward stepwise analysis yielded slightly lower classification rates).

Three different discriminant functions, or roots, were identified in the model. Each root represents a different way of classifying or predicting to which comparison groups girls belonged 
Table 3. Strength of statistical contribution of predictor variables to discriminant analysis model as measured by Wilks'Lambda, partial Lambda, and F-remove ratio values

\begin{tabular}{lcccc}
\hline $\begin{array}{l}\text { Predictor } \\
\text { Variable }\end{array}$ & Wilks' Lambda & Partial Lambda & F-remove & $\mathrm{p}$ \\
\hline $\begin{array}{l}\text { Father's education } \\
\text { Religiosity }\end{array}$ & 0.58 & 0.99 & 1.31 & 0.270 \\
$\begin{array}{l}\text { Weight perception } \\
\text { accuracy }\end{array}$ & 0.59 & 0.97 & 2.83 & 0.038 \\
$\begin{array}{l}\text { Food management } \\
\text { group }\end{array}$ & 0.70 & 0.74 & 35.27 & 0.000 \\
$\begin{array}{l}\text { Self-esteem } \\
\text { group }\end{array}$ & 0.58 & 0.82 & 22.33 & 0.000 \\
& & 0.99 & 1.30 & 0.276 \\
\hline
\end{tabular}

TABLE 4. Classification matrix or percent of correct classification of girls in comparison groups by the predictor variables of father's education, religiosity, weight perception accuracy, food management group, and self esteem group

\begin{tabular}{lc}
\hline Comparison Group & \% Correct Classification \\
\hline I Desiring thinness & 63.86 \\
II Desiring health & 49.28 \\
III Desiring thinness \& health & 44.29 \\
IV Desiring neither thinness or health & $\underline{47.62}$ \\
$\quad$ Total & 51.63 \\
\hline
\end{tabular}


(Table 5). With no roots removed (meaning all roots or ways of classifying girls were measured against one another with respect to statistical strength) the first discriminant function or root was shown to be the most statistically significant, with a chi square value of 166.18 . Once this root was removed, the next strongest root had a chi square of 69.53. Both of these values were significant, while the chi square value of the third root was not significant.

The statistical contribution of each root to the overall classification accuracy of the predictor model is listed in Table 6. In this table, correlations between predictor variables and comparison groups (grouping variables) were standardized into canonical coefficients so that the relative strengths of predictor variables within each discriminant function could be compared with one another.

Of the $51.6 \%$ of girls who were correctly classified into comparison groups, the first discriminant function or root contributed $59.7 \%$ of this classification (shown by its cumulative property in Table 6). This root was best explained by the contribution of the variable of weight perception accuracy, which had the highest canonical coefficient value of all variables in this root. Thus, differences in weight perception accuracy were the major basis in this particular discriminate function of predicting to which comparison groups girls were assigned. The second root was best explained by the variable of food management group, which had the highest canonical coefficient value in this function. By subtracting the cumulative property of the first root, the cumulative property of the second root was found to be $37.4 \%$, indicating that this root accounted for $37 \%$ of the $51.6 \%$ of girls who were correctly classified into comparison groups. Thus, differences in food management group were the main basis for classifying girls into 
TABLE 5. Significance of Eigenvalue, canonical R, Wilks' Lambda, and chi square tests with successive roots removed, in the prediction of comparison groups by the predictor variable model of father's education, religiosity, weight perception accuracy, food management group, and self-esteem group

\begin{tabular}{ccccrr}
\hline Roots Removed & Eigenvalue & $\begin{array}{c}\text { Canonical } \\
\mathrm{R}\end{array}$ & $\begin{array}{l}\text { Wilks' } \\
\text { Lambda }\end{array}$ & $X^{2}$ & $\mathrm{p}$ \\
\hline 0 & 0.38 & 0.52 & 0.58 & 166.18 & 0.000 \\
1 & 0.24 & 0.44 & 0.79 & 69.53 & 0.000 \\
2 & 0.02 & 0.13 & 0.98 & 5.45 & 0.142 \\
\hline
\end{tabular}

TABLE 6. Statistical contribution of the predictor variables of weight perception accuracy, food management group, religiosity, and father's education, and self-esteem group to each discriminant function or root as determined by standardized coefficients for canonical variables

\begin{tabular}{lcrc}
\hline Variable & Root 1 & Root 2 & Root 3 \\
\hline Weight perception accuracy & 0.952042 & -0.363900 & -0.073186 \\
Food management group & 0.450078 & 0.837476 & -0.297989 \\
Religiosity & 0.124531 & -0.194094 & -0.978997 \\
Father's education & -0.135127 & -0.205763 & -0.044958 \\
Self-esteem group & -0.11778 & -0.263143 & -0.023308 \\
Eigenvalue & 0.379356 & 0.237709 & 0.018289 \\
Cumulative property & 0.597079 & 0.971215 & 1.000000 \\
\hline
\end{tabular}


comparison groups in this particular discriminate function.

By subtracting the cumulative properties of roots 1 and 2, the cumulative property of root 3 was found to be approximately $3 \%$. This third root, best explained by the variable of religiosity, did appear to contribute a small amount of discrimination, but, as mentioned, the chi square value for this third root was not significant (Table 5).

Several other predictor models also classified approximately $50 \%$ of comparison groups. In each of these cases, when the variables of either weight perception accuracy or food management group were replaced by other body image and food management behavior variables, prediction rates dropped to $40-43 \%$.

$\underline{\text { Results with Significant Predictor Variables. To determine which comparison groups }}$ were best distinguished from one another by the significant predictor variables, the means of the canonical variables of the three roots were compared with one another (Table 7). Canonical variables were derived from predictor variables and comparison groups. They represent the specific relationships between each of the five predictor variables in the model (weight perception accuracy, food management group, religiosity, father's education, and self-esteem group) and each of the four indicators of thinness and health motivations represented by the four comparison groups.

Analysis indicated that in root 1, the variable of weight perception accuracy seemed to best distinguish groups II and IV from groups I and III. In root 2, the variable of food management group seemed to best distinguish groups II and III from groups I and IV.

With respect to weight perception accuracy, 51\% of girls in group II (desiring health) 
TABLE 7. Differences among comparison groups characterized by the means of the canonical variables of the three roots or discriminant functions

\begin{tabular}{|c|c|c|c|}
\hline Comparison Group & Root 1 & Root 2 & Root 3 \\
\hline I Thinness & 0.738643 & 0.346766 & -0.113755 \\
\hline II Health & -0.810692 & -0.266559 & -0.157624 \\
\hline III Both & 0.395260 & -0.729242 & 0.111380 \\
\hline IV Neither & -0.393329 & 0.484022 & 0.149062 \\
\hline
\end{tabular}


and 39\% of girls in group IV (desiring neither health nor thinness) underestimated their weights while only $13 \%$ of girls in group I (desiring thinness) and $3 \%$ of girls in group III (desiring both thinness and health) underestimated their weights. Forty percent of girls in group I and $41 \%$ of girls in group III overestimated their weights while only 7\% of girls in group II and 5\% of girls in group IV overestimated their weights. Thus, more girls in groups II and IV underestimated their weights than did girls in groups I and III, and more girls in groups I and III overestimated their weights than did girls in groups II and IV (Table 8).

The actual weight/size ranges and average BMI values of girls in each comparison group is shown in Table 9. Actual weight/size range refers to the categories of thin, thinner than average, average, heavier than average, or heavy to which girls belonged based on their BMI values.

Average BMIs of comparison groups II and IV were noticeably higher than average BMIs of girls in comparison groups I and III. These data further illustrate that thinner girls, who tended to overestimate their weight/size ranges, were found predominantly in comparison groups I and III, while heavier girls, who tended to underestimate their weight/size ranges, were found predominantly in comparison groups II and IV.

The variable of food management group discriminated somewhat between comparison groups II and III and groups I and IV. More dieters and dieter/watchers and fewer FMG-neithers were found in groups II and III than were found in groups I and IV, as shown in Table 10. 
TABLE 8. Weight perception accuracy of girls in the four comparison groups of desiring thinness, desiring health, desiring both thinness and health, and desiring neither thinness nor health

\begin{tabular}{|c|c|c|c|c|}
\hline Comparison Group & Underestimate & Accurate & Overestimate & Total \\
\hline I Thinness & 12 & 42 & 36 & 90 \\
\hline II Health & 38 & 32 & 5 & 75 \\
\hline III Both & 2 & 41 & 30 & 73 \\
\hline IV Neither & 34 & 49 & 4 & 87 \\
\hline
\end{tabular}

TABLE 9. Actual weight/ size ranges, average BMI values, and BMI ranges of girls in comparison groups

\begin{tabular}{|c|c|c|c|c|c|c|c|}
\hline \multirow{2}{*}{$\begin{array}{l}\text { Comparison } \\
\text { Group }\end{array}$} & \multicolumn{5}{|c|}{ Weight/Size Range } & \multicolumn{2}{|c|}{ BMI values } \\
\hline & Thin & Thinner & Aver. & Heavier & Heavy & Aver. BMI & BMI Range \\
\hline I Thinness & 25 & 34 & 28 & 5 & 2 & 20.1 & $15.3-32.3$ \\
\hline II Health & 0 & 0 & 27 & 29 & 21 & 24.9 & $20.6-40.4$ \\
\hline III Both & 12 & 23 & 38 & 3 & 0 & 20.5 & $17.5-24.8$ \\
\hline IV Neither & 1 & 1 & 30 & 27 & 29 & 25.6 & $18.9-44.4$ \\
\hline
\end{tabular}


TABLE 10. Food management strategies of dieting, dieting and watching, watching only, and neither dieting nor watching (defined as food management groups), used by girls in the four comparison groups of desiring thinness, desiring health, desiring both thinness and health, and desiring neither thinness nor health

\begin{tabular}{|c|c|c|c|c|c|}
\hline \multirow{2}{*}{ Comparison Group } & \multicolumn{4}{|c|}{ Food Management Group } & \multirow[b]{2}{*}{ Total } \\
\hline & Dieter & $\mathrm{DW}^{\mathrm{a}}$ & Watcher & Neither ${ }^{b}$ & \\
\hline I Thinness & 2 & 12 & 30 & 51 & 95 \\
\hline II Health & 12 & 24 & 32 & 11 & 79 \\
\hline III Both & 8 & 28 & 32 & 8 & 76 \\
\hline IV Neither & 4 & $\underline{13}$ & $\underline{39}$ & $\underline{33}$ & $\underline{89}$ \\
\hline Total & 26 & 77 & 133 & 103 & 339 \\
\hline
\end{tabular}

${ }^{\mathrm{a}}$ dieter/watcher ${ }^{\mathrm{b}}$ FMG-neither 


\section{Other Statistical Analyses and Descriptive Data}

Desire for Thinness, Body Weight Satisfaction, and Weight Loss Desired.

Desire for thinness, defined in this study as desiring or being satisfied with BMI values $<20.4$, was found in this sample population. The numbers of girls who did and did not desire thinness were:

$\begin{array}{lr}\text { Desired thinness } & 176 \\ \text { Did not desire thinness } & 160 \\ \text { Total } & 336 \\ \text { Missing } & 9\end{array}$

The number of girls who desired thinness as compared to their actual weight/size range is shown in Table 11. A majority of one hundred seventy-six girls (52\%) were found to desire thinness. Virtually all girls who were already thin or were thinner than average were satisfied with thinness. Of one hundred twenty-three girls of average weight and size, seventy (57\%) desired thinness, however, only nine girls who were heavy or heavier than average desired thinness.

Body weight dissatisfaction was widespread in this sample. The total number of girls who reported weight satisfaction and dissatisfaction follows:

$\begin{array}{lc}\text { Weight satisfaction } & 84 \\ \text { Weight dissatisfaction } & 245 \\ \text { Total } & 329\end{array}$

Only $25 \%$ of girls in the sample reported being satisfied with their weight. An overall $72 \%$ reported weight dissatisfaction, and 67\% (230 girls) listed specific amounts of weight they wished to lose. Body weight satisfaction and actual weight/size ranges among girls who desired different amounts of weight loss is shown in Table 12.

While the majority of girls who were thin (21 out of 28) desired no weight loss, significant percentages of girls in other BMI categories who were not overweight did desire 
Table 11. Actual weight/size range of girls who desired thinness

\begin{tabular}{lcccccc}
\hline & \multicolumn{6}{c}{ Weight/Size range ${ }^{\text {a }}$} \\
\\
\cline { 2 - 6 } & 1 & 2 & 3 & 4 & 5 & Total \\
Desire for thinness & 37 & 60 & 70 & 8 & 1 & 176 \\
Total in Weight/Size Range & 38 & 62 & 123 & 64 & 52 & 336 \\
\hline
\end{tabular}

${ }^{\mathrm{a}} 1=$ thin, $2=$ thinner than average, $3=$ average, $4=$ heavier than average, $5=$ heavy (based on BMI values)

TABLE 12. Actual weight/size range of girls who desired thinness

\begin{tabular}{|c|c|c|c|c|c|c|c|}
\hline \multirow{2}{*}{$\begin{array}{l}\text { Weight loss } \\
\text { Group }\end{array}$} & \multirow{2}{*}{$\mathrm{n}$} & \multirow{2}{*}{$\begin{array}{l}\text { Wt. } \\
\text { Satisf }^{\text {a }}\end{array}$} & \multicolumn{5}{|c|}{ Weight/Size range ${ }^{b}$} \\
\hline & & & 1 & 2 & 3 & 4 & 5 \\
\hline $0 \mathrm{lb}$. & 83 & 82 & 21 & 23 & 27 & 8 & 4 \\
\hline $1-6 \mathrm{lb}$. & 31 & 0 & 4 & 16 & 7 & 4 & 0 \\
\hline 7-10 lb. & 83 & 0 & 3 & 11 & 56 & 12 & 0 \\
\hline $11-14 \mathrm{lb}$. & 16 & 0 & 0 & 2 & 6 & 7 & 1 \\
\hline $15-20 \mathrm{lb}$. & 48 & 0 & 0 & 3 & 19 & 19 & 7 \\
\hline $21+\mathrm{lb}$ & $\underline{52}$ & $\underline{0}$ & $\underline{0}$ & $\underline{0}$ & $\underline{3}$ & $\underline{11}$ & $\underline{37}$ \\
\hline Totals & 313 & 82 & 28 & 55 & 118 & 61 & 49 \\
\hline
\end{tabular}

${ }^{a}$ number of girls satisfied with their weight

${ }^{\mathrm{b}} 1=$ thin $2=$ thinner than average $3=$ average $4=$ heavier than average $5=$ heavy (based on BMI values) 
weight loss. Forty-nine percent of girls with BMIs in the thinner than average range desired some amount of weight loss, and $77 \%$ of girls with average BMIs also desired weight loss. The majority of girls who were heavy (37 out of 49) desired to lose $21 \mathrm{lb}$. or more.

Girls who wanted to lose 7 to $10 \mathrm{lb}$. constituted the largest (by number) weight loss group, followed by girls who wanted to lose $21 \mathrm{lb}$. or more, and girls who wanted to lose 15 to $20 \mathrm{lb}$. When percentages rather than numbers were compared across weight loss groups, the percentages increased as total desired weight loss increased. Thus, $25 \%$ of girls who were thin, $58 \%$ of girls who were thinner than average, and $77 \%$ of girls who were of average BMI desired weight loss. Among girls whose BMIs were in the heavier than average and heavy ranges, $87 \%$ and $92 \%$ respectively desired weight loss.

One hundred sixteen girls desired weight loss greater than $10 \mathrm{lb}$. Eighty-two of them (71\%), had BMI values that were heavier than average or in the overweight range. Seventy-six percent of these eighty-two girls desired to lose 21 or more lb., but only nine (11\%) desired thinness (Table 11). In contrast, ninety-four out of ninety-nine girls (95\%) who were thin or thinner than average desired or were satisfied with thinness. Thus, most girls who were heavy or heavier than average did not desire unhealthy amounts of weight loss.

Of girls whose BMIs were in the heavy or heavier than average range, more were found to be West Virginia residents than non-residents:

$$
\text { residents non residents }
$$

$\begin{array}{lll}\text { heavier than average BMIs } & 38 & 25 \\ \text { heavy BMIs } & 34 & 18 \\ \text { total } & 72 & 43\end{array}$

Overweight subjects made up $15 \%$ of the overall sample population, and $17 \%$ of the West Virginia resident population. Using ANOVA, a significant relationship between weight 
range and residency was not found.

Using ANOVA, a significant relationship was found between desire for thinness and weight loss group $(\mathrm{F}=13.55, p=0.000)$ such that girls who desired or were satisfied with thinness desired less weight loss. No correlation was found between desire for thinness and weight satisfaction. Both girls who did and did not desire thinness reported weight dissatisfaction.

Self-Esteem and Desire for Weight Loss.

The distribution of self-esteem scores among girls who desired different amounts of weight loss is shown in Table 13. Using ANOVA, self-esteem was found to be significantly related to weight loss group, with a significant $\mathrm{F}$ ratio of 2.51 , and $p=0.047$. Self-esteem scores of girls who desired no weight loss were significantly higher than self-esteem scores of girls who desired weight loss of 7 to $10 \mathrm{lb}$. and $15 \mathrm{lb}$. or more. Of girls desiring no weight loss, $51 \%$ were in self-esteem group 5, the category with the highest self-esteem scores, and $79 \%$ were in selfesteem groups 4 and 5, the two highest categories of self-esteem scores. Of girls desiring a 7 to $10 \mathrm{lb}$. weight loss, only $32 \%$ were in self-esteem group 5, but $71 \%$ were in groups 4 and 5 . Thus, more of these girls were in self-esteem group 4, the second highest category of selfesteem. Of girls who wished to lose 15 or more lb., only $23 \%$ were in self-esteem group 5 and only $50 \%$ were in both self-esteem groups 4 and 5 .

Using ANOVA, no significant correlations were found between self-esteem and desire for thinness, self-esteem and weight satisfaction, self-esteem and food management group, or self-esteem and desire for health. 
TABLE 13. Distribution of self-esteem scores (categorized by self-esteem groups) among girls who desired different amounts of weight loss

\begin{tabular}{lrrrrrr}
\hline Weight Loss Group & \multicolumn{7}{c}{ Self-esteem Group ${ }^{\text {a }}$} \\
\hline & 1 & 2 & 3 & 4 & 5 & Total \\
$0 \mathrm{lb}$. & 0 & 4 & 13 & 22 & 41 & 80 \\
$1-3 \mathrm{lb}$. & 1 & 0 & 0 & 0 & 1 & 1 \\
$4-6 \mathrm{lb}$. & 0 & 9 & 15 & 11 & 10 & 27 \\
$7-10 \mathrm{lb}$. & 0 & 1 & 4 & 8 & 3 & 82 \\
$11-14 \mathrm{lb}$. & 0 & 4 & 14 & 13 & 15 & 46 \\
$15-20 \mathrm{lb}$. & $\underline{4}$ & $\underline{6}$ & $\underline{15}$ & $\underline{14}$ & $\underline{12}$ & $\underline{51}$ \\
$21+\mathrm{lb}$. & $\mathbf{2 5}$ & $\mathbf{6 5}$ & 100 & 108 & 303 \\
Total & & & & & & \\
\hline
\end{tabular}

a ranges of scores on Rosenberg Inventory: $1=14-19 ; 2=20-24 ; 3=25-29 ; 4=30-34$; $5=35-40$. 


\section{Food Management Behavior}

All four food management groups (dieter, dieter/watcher, watcher, and

FMG- neither) were represented in this sample population. The food management group of watchers had the largest number of girls with $39 \%$ of the population, followed by FMG-neithers, which claimed $30 \%$ of the population. Twenty-three percent of girls described themselves as dieter/watchers, and 8\% described themselves as dieters, as shown in Table 10.

Food management group was found to be significantly related to body weight satisfaction by ANOVA. A significant F ratio was found for dieters and weight satisfaction $(\mathrm{F}=5.13, p=0.02)$, for dieter/watchers and weight satisfaction $(\mathrm{F}=7.02, p=0.001)$, and for FMGneithers and weight satisfaction $(\mathrm{F}=8.65, p=0.000)$. FMG-neithers were found to be more satisfied with their weights, while dieters and dieter/watchers were found to be less satisfied with their weights.

The distribution of food management groups among girls who desired different amounts of weight loss is shown in Table 14. Of girls who desired no weight loss, the majority were FMG-neithers (49\%) and watchers (41\%). Of girls desiring 1 to $10 \mathrm{lb}$. of weight loss, $45 \%$ were watchers , followed by dieter/watchers (27\%), and FMG-neithers (20\%). A minority were dieters (8\%). Of girls desiring weight loss of $11 \mathrm{lb}$. or more, a similar pattern was observed, with watchers in the majority followed by dieter/watchers, FMG-neithers, and dieters. However, there were fewer watchers (34\%) and almost twice as many dieters (14\%) in the $11 \mathrm{lb}$. or more weight loss group than in the 1 to $10 \mathrm{lb}$. group (8\%).

One hundred thirty girls desired unnecessary weight loss, as shown by their BMI values of thin to average range (Table 15). Of these girls, fourteen were dieters and thirty-eight were dieter/watchers. Thus, fifty-two girls (50\%) out of a total one hundred three dieters and 
TABLE 14. Food management strategies of dieting, dieting and watching, watching only, and neither dieting nor watching (defined as food management groups), chosen by subjects who desired different amounts of weight loss

\begin{tabular}{|c|c|c|c|c|c|}
\hline \multirow[t]{2}{*}{ Wt Loss Group } & \multicolumn{5}{|c|}{ Food Management Group } \\
\hline & Dieter & $\mathrm{DW}^{\mathrm{a}}$ & Watcher & Nther ${ }^{b}$ & Total \\
\hline $0 \mathrm{lb}$. & 2 & 6 & 34 & 41 & 83 \\
\hline $1-3 \mathrm{lb}$. & 0 & 0 & 1 & 1 & 2 \\
\hline 4-6 lb. & 1 & 7 & 14 & 8 & 30 \\
\hline 7-10 lb. & 8 & 24 & 37 & 14 & 83 \\
\hline 11-14 lb. & 1 & 5 & 7 & 3 & 16 \\
\hline $15-20 \mathrm{lb}$. & 6 & 13 & 19 & 10 & 48 \\
\hline $21+\mathrm{lb}$ & $\underline{9}$ & $\underline{16}$ & $\underline{14}$ & $\underline{13}$ & $\underline{52}$ \\
\hline Total & 27 & 71 & 126 & 90 & 314 \\
\hline
\end{tabular}

a

dieter/watcher

${ }^{\mathrm{b}}$ FMG-neither

TABLE 15. Actual size/weight ranges and food management behaviors of dieting, dieting and watching, watching only, and neither dieting nor watching (defined as food management group) used by girls desiring unnecessary weight loss

\begin{tabular}{lrcccc}
\hline Actual Weight Range & $\mathrm{n}$ & \multicolumn{4}{c}{ Food Management Group } \\
\hline & & Dieter & DW $^{\text {a }}$ & Watcher & Neither \\
& & & & & \\
1 & Thin & 0 & 2 & 0 & 5 \\
2 Thinner than aver. & 32 & 3 & 13 & 12 & 4 \\
3 Average & $\underline{91}$ & $\underline{11}$ & $\underline{23}$ & $\underline{37}$ & $\underline{20}$ \\
$\quad$ Total & 130 & 14 & & & \\
\hline
\end{tabular}

a dieter/watcher 
dieter/watchers in the sample population dieted unnecessarily and desired unnecessary weight loss. Thirty-seven percent of all watchers and 28\% of all FMG-neithers also desired unnecessary weight loss.

Girls' motivations for using different food management behaviors are shown in Tables 16 and 17. Of the twenty-six dieters who ranked their motivations for dieting, a majority of twenty (77\%) chose weight related motivations only. Twelve of fourteen dieters motivated solely by weight loss were in comparison groups II (health) and III (thinness \& health). Of seventy-four dieter/watchers who ranked their motivations for dieting and for watching, 53\% and 52\% respectively reported weight related motivations only.

Of girls who identified themselves as watchers, $64 \%$ reported watching for health reasons, or for a combination of health and weight related reasons, and 33\% watched for weight loss and/or weight maintenance reasons.

Unhealthy food management behaviors used by dieters and dieter/watchers are shown in Table 18. Because girls were asked to check as many dieting strategies as they commonly used, the categories of unhealthy food management behaviors do not necessarily reflect separate groups of girls. For example, girls who ate fewer meals may have also fasted or used diet pills, etc.

The most common unhealthy diet behaviors used by dieters were: eating fewer meals per day (69\%), skipping meals when hungry (58\%), using water pills, diet pills, or laxatives (50\%), and using crash diets (38\%). Fifty-one percent of dieter/watchers ate fewer meals when dieting, $21 \%$ skipped meals when hungry, $19 \%$ used water pills, diet pills, or laxatives, and $14 \%$ used crash diets. 
TABLE 16. Different motivations for dieting used by girls in the four comparison groups desiring thinness, desiring health, desiring both thinness and health, and desiring neither thinness nor health

\begin{tabular}{|c|c|c|c|c|c|c|c|c|c|c|c|c|}
\hline \multirow[t]{3}{*}{$\begin{array}{l}\text { Comparison } \\
\text { Group }\end{array}$} & \multicolumn{6}{|c|}{ Motivations chosen alone $^{a}$} & \multicolumn{4}{|c|}{$\begin{array}{l}\text { Motivations chosen } \\
\text { in combination }{ }^{b}\end{array}$} & \multicolumn{2}{|c|}{ Totals } \\
\hline & \multicolumn{2}{|c|}{ lose wt } & \multicolumn{2}{|c|}{ mntn $w^{c}{ }^{c}$} & \multicolumn{2}{|c|}{ mntn health ${ }^{\mathrm{d}}$} & \multicolumn{2}{|c|}{ health $\& w t^{\mathrm{e}}$} & \multicolumn{2}{|c|}{ wt only ${ }^{\text {f }}$} & \multirow{2}{*}{\multicolumn{2}{|c|}{ D DW }} \\
\hline & $\underline{\mathrm{D}^{\mathrm{g}}}$ & $\mathrm{DW}^{\mathrm{h}}$ & $\mathrm{D}$ & DW & & DW & $\mathrm{D}$ & DW & $\mathrm{D}$ & DW & & \\
\hline I Thinness & 2 & 2 & 0 & 0 & 0 & 1 & 0 & 4 & 0 & 3 & 2 & 10 \\
\hline II Health & 6 & 5 & 0 & 1 & 0 & 1 & 4 & 11 & 2 & 6 & 12 & 24 \\
\hline III Both & 6 & 8 & 0 & 0 & 0 & 0 & 1 & 15 & 1 & 4 & 8 & 27 \\
\hline IV Neither & 0 & 9 & 0 & 0 & 0 & 0 & 1 & 2 & 3 & 2 & 4 & 13 \\
\hline Totals & 14 & 24 & 0 & 1 & 0 & 2 & 6 & 32 & 6 & 15 & 26 & 74 \\
\hline
\end{tabular}

a girls who chose only one of these motivations.

${ }^{b}$ girls who chose a combination of motivations.

${ }^{\mathrm{c}}$ maintain weight.

d maintain health.

e health and weight motivations

f weight loss and weight maintenance motivations (no health motivations).

g dieter.

h dieter/watcher 
TABLE 17. Different motivations for watching what they ate used by girls in the four comparison groups of desiring thinness, desiring health, desiring both thinness and health, and desiring neither thinness nor health

\begin{tabular}{|c|c|c|c|c|c|c|c|c|c|c|c|c|}
\hline \multirow[t]{3}{*}{$\begin{array}{l}\text { Comparison } \\
\text { Group }\end{array}$} & \multicolumn{6}{|c|}{ Motivations chosen alone $^{\mathrm{a}}$} & \multicolumn{4}{|c|}{$\begin{array}{l}\text { Motivations chosen } \\
\text { in combination }{ }^{\mathrm{b}}\end{array}$} & \multicolumn{2}{|c|}{ Totals } \\
\hline & \multicolumn{6}{|c|}{ lose wt mntn wt ${ }^{\mathrm{c}}$ mntn health } & \multicolumn{4}{|c|}{ health \& wt ${ }^{\mathrm{e}} \quad$ wt only ${ }^{\mathrm{f}}$} & \multirow{2}{*}{\multicolumn{2}{|c|}{ DW W }} \\
\hline & $\underline{\mathrm{DW}^{\mathrm{g}}}$ & $\mathrm{W}^{\mathrm{h}}$ & DW & $\mathrm{W}$ & DW & $\mathrm{W}$ & $\underline{\text { DW }}$ & $\mathrm{W}$ & DW & $\mathrm{W}$ & & \\
\hline I Thinness & 4 & 4 & 0 & 3 & 0 & 3 & 5 & 14 & 2 & 6 & 11 & 30 \\
\hline II Health & 6 & 5 & 0 & 1 & 1 & 1 & 9 & 21 & 6 & 1 & 22 & 29 \\
\hline III Both & 6 & 2 & 1 & 1 & 0 & 1 & 11 & 20 & 4 & 5 & 22 & 29 \\
\hline IV Neither & 7 & 4 & 0 & 1 & 0 & 1 & 8 & 19 & 3 & 6 & 18 & 31 \\
\hline Totals & 23 & 15 & 1 & 6 & 1 & 6 & 11 & 42 & 15 & 18 & 73 & 119 \\
\hline
\end{tabular}

${ }^{a}$ girls who chose only one of these motivations.

${ }^{b}$ girls who chose a combination of motivations.

${ }^{c}$ maintain weight.

${ }^{\mathrm{d}}$ maintain health.

${ }^{\mathrm{e}}$ health and weight motivations

${ }^{\mathrm{f}}$ weight loss and weight maintenance motivations (no health motivations).

g dieter/watcher.

${ }^{\mathrm{h}}$ watcher 
TABLE 18. Specific food management behaviors preferred or used most frequently by dieters and dieter/watchers that were considered to be unhealthy behaviors

\begin{tabular}{|c|c|c|c|c|c|c|c|}
\hline \multirow{2}{*}{$\begin{array}{l}\text { Food management } \\
\text { Group (FMG) }\end{array}$} & \multicolumn{7}{|c|}{ Food management behavior (FMB) } \\
\hline & $\begin{array}{l}\text { Fewer } \\
\text { meals }\end{array}$ & $\begin{array}{l}\text { skip when } \\
\text { hungry }\end{array}$ & fast & $\begin{array}{c}\text { water/diet } \\
\text { pills }\end{array}$ & $\begin{array}{l}\text { crash } \\
\text { diets }\end{array}$ & vomit & $\begin{array}{r}\text { liquid } \\
\text { diets }\end{array}$ \\
\hline Dieter total $^{\mathrm{a}}$ & 18 & 15 & 8 & 13 & 10 & 3 & 6 \\
\hline Used freq ${ }^{\mathrm{b}}$ & 16 & 13 & 8 & 13 & 10 & 3 & 6 \\
\hline $\mathrm{D} / \mathrm{W}^{\mathrm{c}}$ total $^{\mathrm{d}}$ & 39 & 16 & 7 & 15 & 11 & 4 & 2 \\
\hline Used freq $^{\mathrm{e}}$ & 28 & 10 & 3 & 10 & 5 & 2 & 2 \\
\hline $\begin{array}{l}\text { Total who } \\
\text { used FMB }^{\mathrm{f}}\end{array}$ & 57 & 31 & 15 & 28 & 21 & 7 & 8 \\
\hline $\begin{array}{l}\text { Total who } \\
\text { used FMB } \\
\text { frequently }\end{array}$ & 44 & 23 & 11 & 23 & 15 & 5 & 8 \\
\hline
\end{tabular}

a total number of dieters who used each food management behavior (FMB) as a preferred or frequent method when dieting

${ }^{b}$ number of dieters who used each FMB as a preferred or frequent method when dieting and who dieted frequently ( 2 or more times per week) or always

c dieter/watcher

d total number of dieter/watchers who used each FMB as a preferred or frequent method when dieting

${ }^{\mathrm{e}}$ number of dieter/watchers who used each FMB as a preferred or frequent method when dieting and who dieted frequently ( 2 or more times per week) or always

f total number of dieters and dieter/watchers who used each FMB

$\mathrm{g}$ total number of dieters and dieter/watchers who preferred to use each FMB when dieting and who dieted frequently or always 
With respect to the entire population sample, the percentage of girls who ate fewer meals when dieting was $16 \%$, the percentage of those who skipped meals when hungry was $9 \%$, and the percentage of girls who used diet pills, diuretics, or laxative pills was $8 \%$. Girls who used crash diets made up $6 \%$ of the overall population. Girls who used all liquid diets and girls who reported symptoms of bulimia (who reported that they intentionally vomited after meals as a diet strategy) each made up $2 \%$ of the population.

Almost all dieters who reported using any of these unhealthy behaviors reported dieting frequently or always. In addition, at least $50 \%$ of dieter/watchers who used these behaviors reported using most of them frequently. Fasting and crash diets were the two behaviors used more frequently by dieters than by dieter/watchers.

Using ANOVA to examine differences among dieters, a significant relationship between dieters who desired thinness and dieters who did not desire thinness was found with respect to food management behavior. Significantly more dieters who desired thinness skipped meals when hungry $(\mathrm{F}=5.94, p=0.022)$ and exercised intensively $(\mathrm{F}=4.73, p=0.039)$ than did dieters who did not desire thinness.

Using ANOVA, significant correlations between desire for weight loss and unhealthy dieting behaviors were not found except in the case of eating fewer meals $(\mathrm{F}=3.84, p=0.001)$. Girls who desired no weight loss were found to use this behavior significantly less often than did girls who desired weight loss of $15 \mathrm{lb}$. or more. No significant differences were found between girls who wanted to lose more than $10 \mathrm{lb}$. and girls who wanted to lose $10 \mathrm{lb}$. or less with respect to unhealthy dieting behaviors. 


\section{Body Image Motivations}

Girls' motivations for desiring particular body images are listed in Table 19. No significant differences were found among comparison groups with respect to body image motivations. The largest body image motivation group consisted of girls who chose both appearance and health as their motivations for desiring a particular body image. Forty-six percent of all girls chose this combination of factors. The majority of girls in this body image motivation subgroup were in comparison groups I (thinness), III (thinness \& health), and IV (neither thinness or health). The second largest body image motivation group consisted of girls who chose health factors alone as their motivations for wanting a particular body image. Thirty percent of all girls who ranked body image motivations chose this subgroup. Distribution of girls in this subgroup across comparison groups was fairly equal, with a few more in comparison group II (health).

Only $6 \%$ of girls cited appearance as their only motivating factor for desiring a particular body image. No girls from comparison group III (thinness \& health) cited appearance as their only motivating factor. Eighteen percent of all girls reported that body image was unimportant to them.

\section{$\underline{\text { Desire for Health }}$}

Differences in involvement with health, from awareness to active involvement, were found in the sample population. Motivations associated with desiring or not desiring a healthy diet and lifestyle and the number of girls who subscribed to these are shown in Table 20. Fiftyseven percent of girls stated that they were trying to do a better job of following a healthy diet and lifestyle, but $50 \%$ stated that doing so was not a priority. Thirty-two percent reported that they were actively involved in following a healthy diet and lifestyle. 
TABLE 19. Body image motivations among girls in the four comparison groups of desiring thinness, desiring health, desiring both thinness and health, and desiring neither thinness nor health

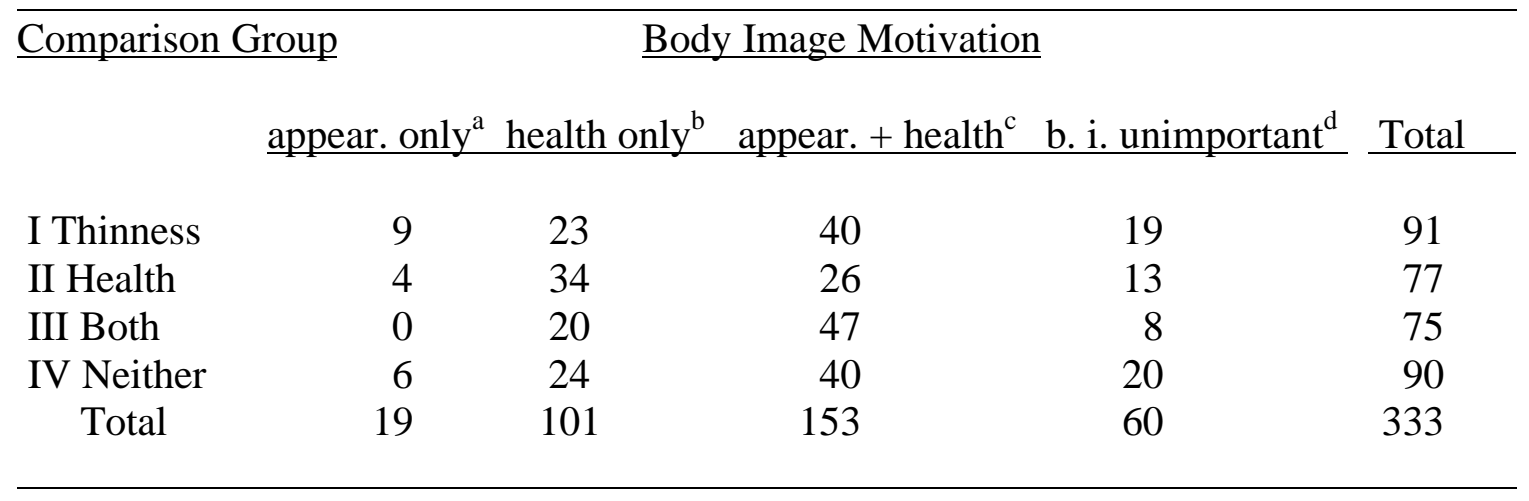

${ }^{a}$ girls motivated by appearance only.

${ }^{b}$ girls motivated by health only.

${ }^{c}$ girls motivated by both appearance and health.

${ }^{d}$ girls who said body image was unimportant. 
TABLE 20. Number of girls in the sample population who subscribed to different motivations that may be associated with desire or lack of desire for health

Health motivation $\quad n$

a) Actively involved in following healthy diet and lifestyle 112

b) Good idea to follow a healthy diet and lifestyle but it is not a priority 173

c) Following a healthy diet \& lifestyle doesn't make a difference in my 13 health

d) Trying to be do a better job of following a healthy diet and 196 lifestyle because health is important

e) Don't know or think much about health, diet, or lifestyle 20

f) Not important to follow healthy diet and lifestyle now, but probably 26 will be when I'm older

d) Number of girls who checked a and d $\quad 49$

e) Number of girls who checked b and d 98 
Using ANOVA, a significant relationship was found between residency and girls who said that they did not know or think much about their health and diet. $(\mathrm{F}=4.07, p=0.044)$. Significantly more West Virginia residents selected this choice than did non-residents. Residency was not found to be significantly related to any other health motivation. 


\section{DISCUSSION}

\section{Discriminate Analysis}

The ability of the predictor variables of body weight satisfaction, self-esteem, SES, and food management behavior to successfully distinguish girls who desired thinness and health alone or in combination was poor. Neither body weight satisfaction nor self-esteem were found to have significant predictive power in distinguishing comparison groups from one another. Only one socioeconomic variable, religiosity, was found to have a small positive effect on prediction. Weight perception accuracy and food management behavior were the only variables that did distinguish among girls in this sample but only to a modest degree. Discussion of all predictor variables follows:

\section{Body Image Variables}

Body Image Satisfaction. Body image satisfaction, represented in this study by body weight satisfaction, was found to be a poor predictor because an overwhelming majority of girls (72\%) reported body weight dissatisfaction. Dissatisfaction was reported by those who did and did not desire thinness or health, and by those who were thin, average and heavy.

Weight Perception Accuracy. Weight perception accuracy was the strongest predictor variable in the discriminate model. It distinguished between girls with higher BMI values, some of whom underestimated their weight range, and girls of lower BMI values, some of whom overestimated their weight range. Most girls with higher BMIs were found in comparison groups II and IV, and most girls with lower BMIs were found in comparison groups I and III. The fact that some thinner girls overestimated their weight range and some heavier girls underestimated their weight range supports the results of Gray (1977) who found that both underweight and overweight people tended to normalize their weights, and the results of Cash and Green (1986), 
Dolan, Birtchnell, and Hubert (1987), who found that underweight girls tended to overestimate their weight.

\section{$\underline{\text { Self-Esteem Variable }}$}

Although female adolescent body image appearance and satisfaction have been shown to be integrally related to self-concept and self-esteem (Franzoi \& Shields, 1984; Secord \& Jourard, 1953; Wooley \& Roll, 1991), self-esteem was not found to be a significant predictor of girls in comparison groups. This may imply that self-esteem was not a key factor in how girls defined desire for thinness and for health, or that separation between these motivations was not accurate enough, and so assignment to comparison groups was not made accurately enough. Support for this latter supposition may be found in the significant differences in self-esteem that were found across weight loss groups. The variable of weight loss group may be thought of as a more specific version of degree of body weight satisfaction. Significantly fewer girls who wanted to

lose 7 to $10 \mathrm{lb}$. and $15 \mathrm{lb}$. or more had self-esteem scores in the highest bracket than did girls who wanted to lose no weight and who reported body weight satisfaction. These data indicate that girls who reported body weight satisfaction had higher self-esteem scores, supporting the results of Harter (1988), Berscheid et al. (1973), and Wendel and Lester (1988). Yet these differences in self-esteem in girls who expressed general body weight satisfaction were not clearly separated across comparison groups. Thus, better classification of girls in comparison groups may have allowed self-esteem to have been a significant predictor. 


\section{$\underline{\text { SES Variables }}$}

Father's Education. This variable did not contribute in a significant way to the prediction of girls in comparison groups, but it was a part of the predictor model found to be most successful at prediction. Exclusion of this variable caused a decrease in prediction rate, thus, it had some relationship with thinness and health motivations. The variable of mother's education,

previously found to be related to healthy food management behavior by Lowry et al. (1996), had no discernable effect on prediction in this study.

Religiosity. This variable had a significant F-remove value, indicating that differences in religiosity did contribute to the discriminant model. The third discriminant function or root, to which religiosity contributed the most discrimination, however, was not found to add any significant overall prediction.

$\underline{\text { Food Management Variable }}$

The finding by Nichter et al. (1995) that some adolescent girls divided the term "dieting" into several different food management behaviors was well supported by the results of this study. The variable of food management group contributed a small amount of differentiation between comparison groups II and III and groups I and IV. More dieters and dieter/watchers and fewer FMG-neithers were found in groups II (health) and III (thinness \& health) than were found in groups I (thinness) and IV (neither thinness nor health). Thus, girls concerned about health and about thinness and health were more involved with dieting than were girls who were concerned about thinness or about neither thinness nor health.

That girls who valued thinness would be less likely to diet is a result that would seem to contradict the results of previous researchers (French et al., 1995; Greenfield et al., 1987; Killen et al., 1994; Lundholm \& Littrell, 1986). Only $2 \%$ of girls in comparison group I described 
themselves as dieters. A larger proportion, 13\%, described themselves as dieter/watchers, but the largest percentage of girls in this group (54\%) were FMG-neithers. These results may be explained by the distribution of weight ranges among girls in this group. Eighty-seven girls out of the total ninety-four in this group were thin, thinner than average, or of average weight, and only seven were heavy or of heavier than average weight. The relatively low proportion of girls who dieted and dieted-and-watched compared to those who did neither, suggests that most of these girls were naturally thin and did not have to work at thinness. These results may also explain the correlation found between desire for thinness and weight loss group such that girls who desired thinness desired less weight loss. Girls who are already naturally thin would be more likely to desire less weight loss or be more satisfied with their weight. The data support this latter conclusion: $60 \%$ of girls who were thin and $50 \%$ of girls who were thinner than average in this comparison group were satisfied with their weight. These subgroups contained the largest percentages of girls in any subgroups who were satisfied with their weight. These data suggest that at least for some girls, body weight satisfaction is related to thinness, supporting the findings of Cohen et al. (1987), Dolan et al. (1987), and Cash and Green (1986).

Since comparison group II consisted of girls concerned about health, and watching has been shown to be associated with health motivations (Nichter et al., 1995), this group might have been expected to have more watchers, fewer dieters and dieter/watchers, and more girls who used these food management groups for health reasons. Group II would have also been expected to have had fewer dieter and dieter/watchers than comparison group III, which consisted of girls who valued thinness in addition to health. Valuing thinness would have presumably motivated an increased number of girls in comparison group III to diet, according to the results of Shaw and Kemeny (1989) and Lundholm and Littrell (1986). Since comparison group I valued only 
thinness and not health, a higher percentage of dieters and dieter/watchers would have been expected in comparison group I than the percentage found in comparison group III.

Results confirmed some of these predictions and contradicted others. That both comparison groups II and III had more dieters and dieter/watchers than comparison group I (desiring thinness) has already been explained by the high number of girls in comparison group I who were probably naturally thin and did not need to diet. There were roughly three times more watchers than dieters or FMG-neithers in both comparison groups II and III, as anticipated, but many were not motivated by health. Further, the variable of food management group provided no significant discrimination between these two groups. One possible explanation for this is the existence of a fifth subgroup within comparison group II that valued appearance and health. Group II had the largest sub-group of dieters (15\%) of all four groups, and the second largest group of dieter/watchers (30\%). Of this sub-population of dieters and dieter/watchers, almost twice as many girls reported that their main motivation for dieting was to lose weight than girls who reported that their main motivation was to maintain their health. Seventy-five percent of the dieter/watchers also watched to lose weight. Fifty percent of both dieters and dieter/watchers ranked appearance as their most important motivation for having a particular body image, implying that they were motivated to lose weight for the sake of appearance. All of these girls reported that following a healthy diet and lifestyle was important because health was important to them, and none reported desiring thinness. These data indicate that a number of girls may have valued both appearance and health. The similarities between comparison group II and III with respect to food management behavior may be explained in part by this fifth subgroup of girls whose motivations may have differed from the motivations of girls in comparison group III only by degree. 
Discriminate analysis did distinguish among differences between comparison group IV and comparison groups II and III with respect to food management group, but, again, only to a small degree. A small percentage of dieters and dieter/watchers and a higher percentage of FMGneithers would have been expected in comparison group IV, since food management behaviors have been found to be associated with appearance and health motivations (Killen et al, 1994; Nichter et al., 1995; Rozin \& Fallon, 1988), and this comparison group was supposed to have neither of these motivations. Although a relatively large percentage of girls in this group did describe themselves as FMG-neithers (37\%), a surprising number described themselves as dieters, dieter/watchers, and watchers. Nineteen percent of girls in comparison group IV described themselves as dieters or dieter/watchers. This was a lower percentage than the percentages of dieters and dieter/watchers in other groups, but was still a substantial percentage. The biggest surprise, however, was that the largest percentage of girls in this group described themselves as watchers $(44 \%)$. Sixty-nine percent of these watchers, (30\% of all girls in this group), reported that at least one of their main motivations for watching was to maintain their health. In addition, a majority of both watchers and FMG-neithers in this comparison group reported being motivated by health factors or by a mix of health and appearance factors in desiring a particular body image. Fifty-nine percent of the watchers and $42 \%$ of the FMGneithers from this comparison group stated that they were trying to do a better job of following a healthy diet and lifestyle. Yet almost all of these girls also stated that following a healthy diet and lifestyle was not a priority for them at present.

The presence of a large group of watchers in comparison group IV, many of whom were motivated at least in part by health, suggests again that assignment to comparison groups based on motivations for thinness and health may not have been accurate enough. This may be further 
supported by the presence of a significant number of dieters and dieter/watchers in the group. Presumably, girls did not describe themselves as dieters or dieter/watchers without having some motivation related to weight and/or appearance. Their presence in this group suggests again that some girls may have belonged to a fifth and/or sixth subgroup that valued appearance and health, or just appearance (but not thinness). In addition, the contradictory results concerning health motivations in this group suggest that some girls had trouble distinguishing among their motivations. Answers were not always internally consistent. All of these factors may have diminished the predictive power of the food management variable.

\section{Descriptive Data}

\section{Desire for Thinness and Health}

Both desire for thinness and desire for health were found to exist in this sample of female adolescents. A group of girls who desired both thinness and health and a group who desired neither thinness nor health were also identified.

A majority of girls (52\%) were found to desire or be satisfied with thinness, defined in this study as BMI values that were thinner than average. Ninety-five girls (28\%) were assigned to comparison group I (desiring thinness) and seventy-six girls (22\%) were assigned to comparison group III (desiring thinness and health). Desire for thinness may be best illustrated by the data on girls who wished to lose 7 to $10 \mathrm{lb}$. Eighty-three girls reported wanting to lose 7 to $10 \mathrm{lb}$., constituting the largest weight loss group in the sample. Sixty-eight percent of girls in this group were of average weight while $17 \%$ were thin or thinner than average, making weight loss unnecessary for $85 \%$ of these girls. Yet more girls in this weight loss group (66\%) desired thinness than desired it in any other weight loss group. 
Desire for health was also found to exist in this population of adolescents and was indicated by several different types of information. First, seventy-nine girls (23\%) were assigned to comparison group II (desiring health) because they reported that they followed a healthy diet and lifestyle or were trying to do a better job of following a healthy diet and lifestyle. Girls also included health as one of their motivations for using different food management behaviors and for desiring particular body images. Thirty-four dieter/watchers (44\%) ranked health as one of their main reasons for dieting, and forty-two watchers (35\%) ranked health as one of their main reasons for watching. Forty-six percent of all girls ranked health factors in combination with appearance factors as important in desiring a particular body image, and $30 \%$ chose health factors as their only motivations for desiring a particular body image.

That some girls may equate thinness with health was demonstrated by the results on girls in comparison group III ( desiring both thinness and health). Girls were assigned to this group if they valued both thinness and health, but assignment alone did not indicate whether they viewed these factors as interrelated functions or as separate entities. The data indicate that some of these girls may have viewed thinness and health as interrelated functions. Eighty-nine percent of girls in this group selected health and appearance factors or health alone as their motivations for wanting a thin body image. No girls in this group selected appearance factors alone for wanting a thin body image. Thus, health was perceived as an important reason for desiring a thin body image. Further, more than $50 \%$ of girls who were dieter/watchers and watchers in this comparison group reported that maintaining their health was one of their main motivations for using their respective food management behaviors. Presumably, they followed these food management behaviors in order to achieve or maintain their desired (thin) body images, and again, health was a motivating factor in both the food management behavior and the body image 
goal. These results suggest that many of the girls in this group perceived thinness as a desirable state of health.

\section{Desire for Thinness and Weight Loss}

Girls who were concerned about thinness tended to have lower BMIs than girls who were not concerned about thinness. From these data, it seems that thin and heavy girls desired weight ranges that were reasonable for them to achieve: only nine girls $(8 \%)$ of one hundred sixteen who were heavy or of heavier than average weight desired thinness, whereas ninety-four girls (98\%) out of ninety-six who were thin or of thinner than average weight desired or were satisfied with thinness. Seventy girls out of one hundred twenty-three (57\%) who were of average weight desired thinness, perhaps because it was within reach. Many of these girls of average weight were in the previously discussed 7 to $10 \mathrm{lb}$. weight loss group. $\underline{\text { Relationship of Body Weight Satisfaction to Dieting Behavior }}$

A major implication of previous researchers' results was that girls with body weight dissatisfaction were more likely to resort to the use of chronic dieting and other unhealthy food management behaviors in their quest for the perfect (thin) body (Collins, 1988; Story, Resnick, \& Blum, 1995). Since body weight dissatisfaction was so widespread in this sample population (72\% of all girls), a large number of dieters and a high frequency of use of unhealthy food management behaviors might have been expected.

Of the two hundred forty-five girls who reported body weight dissatisfaction, a smaller group of one hundred thirty girls (40\% of all girls) desired unnecessary weight loss (had BMIs of thin, thinner than average, or average). Of these one hundred thirty girls, fifty-two were dieters or dieter/watchers. These fifty-two girls constituted $21 \%$ of the of the two hundred forty-five that reported body weight dissatisfaction and $15 \%$ of the entire sample population. These percentages 
do not signify a majority; thus, the data did not support the premise that widespread body weight dissatisfaction leads to or is related to widespread unnecessary dieting. These percentages of girls do, however, represent a significant minority of individuals who were indulging in unnecessary restriction of food. Of these fifty-two dieters and dieter/watchers who desired unnecessary weight loss, one third of them (17) desired to lose more than $10 \mathrm{lb}$. These data indicate that there may be a need for more education about healthy body image, weight loss and food management behavior for some girls in the north-central West Virginian population.

Desire for Weight Loss, Desire for Thinness, and Use of Unhealthy Food Management $\underline{\text { Behaviors }}$

No relationship was found between degree of desired weight loss and more frequent use of unhealthy food management behaviors. No relationship was found between desire for thinness and use of unhealthy food management behaviors. The majority of girls in the population sample were watchers and FMG-neithers, categories which by definition indicated the use of healthy food management behaviors or absence of involvement with food management behavior. Nevertheless, a sizeable minority of girls did diet either alone or in combination with watching what they ate (30\%). Further, there were significant differences in the number of dieters among girls who desired different amounts of weight loss. Almost twice as many girls who wanted to lose $11 \mathrm{lb}$. or more were dieters (14\%) than were girls who wanted to lose $10 \mathrm{lb}$. or less $(8 \%)$. Results indicated that a significant number of these dieters and dieter/watchers girls did use unhealthy food management behaviors.

Sixty-nine percent of dieters ate fewer meals when dieting, 58\% skipped meals when hungry, and 50\% reported using diet pills when dieting. Thirty-eight percent used crash diets. The percentages of dieter/watchers who used these behaviors were smaller, but still substantial 
with respect to eating fewer meals (51\%) and skipping meals when hungry (21\%). An overall $17 \%$ of all girls in the sample ate fewer meals when dieting. These results support previous findings that female adolescent dieting may be associated with unhealthy food management behaviors and that girls who want to lose large amounts of weight are more likely to diet and more likely to use unhealthy food management behaviors (French et al.,1995; Killen et al., 1993; Moreno, 1995; Searles et al., 1986; Storz \& Greene, 1983).

\section{Implications and Conclusions}

The low predictive power of the variables in discriminate analysis may have been due to a number of factors. The use of body weight satisfaction as a predictor may have been a poor choice in light of the widespread expression of body weight dissatisfaction in the female adolescent population. Because expression of weight dissatisfaction is so much a part of current female adolescent culture, distinctions between cultural and genuine expressions of dissatisfaction may be impossible to make. Differences between desire for thinness and desire for appearance may not have been significant enough to have distinguished groups of girls from one another. Desire for thinness may not have been defined well enough; there may have been differences in motivations between girls who desired thinness and girls who were satisfied with already being thin. Regional and cultural differences may have affected distribution and responses to SES and self-esteem variables. Survey questions asked may not have been clear enough to yield accurate information about motivations, thus, girls may not have been accurately assigned to comparison groups. Age may have also been a factor; perhaps differences in certain variables would have been more pronounced in younger adolescents, who have had less exposure as well as less experience in dealing with cultural messages of all kinds. 
Some girls gave internally inconsistent answers, thus illustrating another difficulty in trying to identify female adolescent motivations for desiring health or appearance. Girls may have been unable to make clear distinctions between their appearance and health motivations, or, conversely, they may have perceived significant differences in their motivations to variables that would have seemed on the surface to have been associated with similar motivations. While desiring health was determined from specific answers to question \#30, which asked girls whether following a healthy diet and lifestyle was important to them, health motivations were also solicited in question \#16, in which girls were asked to define their motivations for wanting a particular body image, and from some answers to question \# 31, in which motivations of FMGneithers were solicited. Answers to these questions were sometimes contradictory and puzzling. Some girls seemed to make important distinctions between the concepts of diet and health and between the concepts of desiring a healthy body and desiring a healthy lifestyle. Questions worded differently may have yielded more internally consistent answers and allowed for better separation among comparison groups.

The difficulties in clarifying motivations in this study illustrate some of the shortcomings of using survey questionnaires. Because of these difficulties, results must be interpreted with caution. Further, because each population sample may be unique in certain ways, it may be a mistake to assume that all local results can be generalized to the larger population. In this study, many of the girls found to desire only thinness were already naturally thin. Their behaviors and motivations may not be representative of girls who desire thinness in other regions of the country.

Despite the difficulties in classifying girls according to their desire for health, this motivation was clearly demonstrated to exist in this sample population. The number of girls who 
said they did not think or know much about health was small- $6 \%$. While significantly more of this $6 \%$ were West Virginia residents than were non residents, the vast majority of girls, both residents ands non residents, reported having some awareness of health issues, even if following a healthy diet and lifestyle was not a priority for them.

The sample population in this study, however, consisted almost entirely of college students who, presumably, were better educated and more motivated than is the general population. Because so few girls involved in vocational pursuits participated in the study, no generalizations can be made about the greater regional female adolescent population. According to the West Virginia Behavioral Risk Factor Survey (West Virginia Department of Health and Human Resources, 1996), native West Virginians with fewer than twelve or sixteen years of education have higher rates of obesity and other health risk factors and behaviors. Thus, for example, while the incidence of $17 \%$ obesity in this sample population was significantly lower than the overall $38 \%$ incidence of obesity in West Virginia, it would be misleading to place too much emphasis on this result in light of the educational bias of the sample. Further study of girls still at the high school level and of high school graduates who are not college students would be of value in gathering more information about motivations for health and thinness that may exist in the West Virginia female adolescent population.

In conclusion, the results of this study show that desire for thinness and health, alone and in combination with one another, did exist in this sample population of eighteen and nineteen year old female adolescents. The use of different food management behaviors first described by Nichter et al. (1995) was clearly demonstrated in this sample as well. Fifty-two percent of girls were satisfied with or desired thinness and $72 \%$ reported weight dissatisfaction. Despite these high percentages, relatively few girls used unhealthy dieting behaviors. Among dieters and 
dieter/watchers, who made up $30 \%$ of the population sample, a substantial minority of girls did use some unhealthy food management behaviors. No significant differences in body weight satisfaction, self-esteem, and SES were found among groups who desired thinness or health. When used as predictor variables, these factors were unable to distinguish girls who desired thinness and health from one another. The variables of weight perception accuracy and food management group did predict comparison groups, but only to a modest extent.

Responses by female adolescents in this study suggest that their concepts of health may be multidimensional. Further research is needed to clarify how female adolescents view health as it relates to diet, lifestyle, food management behavior, and body image. 


\section{REFERENCES}

Adams G., Gullotta T., \& Markstrom-Adams C., (1994). Adolescent Life Experiences. ( $^{\text {rd }}$ ed.). California: Brooks/Cole Publishing Company.

Adler N., Boyce T., Chesney M., Cohen S., Folkman S., Kahn R.L., \& Syme S.L. (1994). Socioeconomic status and health. American Psychologist, 49, 15-24.

Alonzo A. (1993). Health behavior: issues, contradictions, and dilemmas. Social Science and Medicine, 37, 1019-1034.

Backett K., \& Davison C. (1995). Lifecourse and lifestyle: the social and cultural location of health behaviors. Social Science and Medicine, 40, 629-638.

Barnes M., \& Farrier S. (1985). A longitudinal study of the self-concept of low-income youth. Adolescence, 20, 199-205.

Ben-Tovim D., \& Walker M. (1994). The influence of age and weight on women's body attitudes as measured by the Body Attitudes Questionnaire. Journal of Psychosomatic Research, 38, 477-481.

Berscheid E., Walster E., \& Bohrnstedt G. (1973). The happy American body: a survey report. Psychology Today, November, 119-131.

Beaumont P., Al-Alami M., and Jouyz S. (1988). Relevance of a standard measurement of undernutrition to the diagnosis of anorexia nervosa: use of Quetelet's Body Mass Index. International Journal of Eating Disorders, 7, \#3, 399- 405.

Blane D. (1995). Social determinants of health- socioeconomic status, social class, and ethnicity. American Journal of Public Health, 85, 903-904.

Brodie D., Bagley K., \& Slade P. (1994). Body image perceptions in pre and post adolescent females. Perceptual and Motor Skills, 78, 147-154.

Butters J., \& Cash T. (1987). Cognitive-behavioral treatment of women's body-image dissatisfaction. (1987). Journal of Consulting and Clinical Psychology, 55, 889-897.

Cash T., \& Green G. (1986). Body weight and body image among college women: perception, cognition, and affect. Journal of Personality Assessment, 50, 290-301.

Cash T., Winstead B., \& Janda L. (1986). The great American shape-up. Psychology Today, 20 (4), 30-37. 
Centers for Disease Control. (1992). Selected tobacco-use behaviors, dietary patterns among high school students- United States 1991. Journal of the American Medical Association, 268 (July 22/29), 448-451.

Centers for Disease Control. (1994). Health risk behavior among persons aged 12-21 yearsUnited States 1992. Journal of the American Medical Association, 271 (May 14), 1311.

Cohn L., Adler N., Irwin C., Millstein S., Kegeles S., \& Stone G. (1987). Body-figure preferences in male and female adolescents. Journal of Abnormal Psychology, 96, 276-279.

Collins M. (1988). Education for healthy body weight: helping adolescents balance the cultural pressure for thinness. Journal of School Health, 58, 227-231.

Damhorst M., Littrell J., \& Littrell M. (1987). Age differences in adolescent body satisfaction. Journal of Psychology, 121, 553-562.

Davies E., \& Furnham A. (1986). The dieting and body shape concerns of adolescent females. Journal of Child Psychology and Psychiatry and Allied Disciplines, 27, 417-428.

Davis S., Winkleby M., \& Farquhar J. (1995). Increasing disparity in knowledge of cardiovascular risk factors and risk-reduction strategies by socioeconomic status: implications for policymakers. American Journal of Preventive Medicine, 11, 318-323.

Dawson D. (1988). Ethnic differences in female overweight: data from the 1985 National Health Interview Survey. American Journal of Public Health, 78, \#10, 1326-1329.

Diehr P., Koepsell T., Cheadle A., Psaty B., Wagner E., \& Curry S. (1993). Do communities differ in health behaviors? Journal of Clinical Epidemiology, 46, 1141-1149.

Dielman T., Leech S., Lorenger A., \& Horvath W. (1984). Health locus of control and selfesteem as related to adolescent health behavior and intentions. Adolescence, 19, 935-950.

Dolan B., Birtchnell S., \& Hubert L. (1987). Body image distortion in non eating disordered women and men. Journal of Psychosomatic Research, 31, 513-520.

Downs A. C., \& Harrison S. (1985). Embarrassing age spots or just plain ugly? Physical attractiveness stereotyping as an instrument of sexism on American television commercials. Sex Roles, 13, 9-19.

Dwyer J., Feldman J., Seltzer C., \& Mayer J. (1969). Adolescent attitudes toward weight and appearance. Journal of Nutrition Education, 1, 14-19.

Elias M. (1990). The role of affect and social relationships in health behavior and school health curriculum and instruction. Journal of School Health, 60, 157-163. 
Fallon A., \& Rozin P., (1985). Sex differences in perceptions of desirable body shape. Journal of Abnormal Psychology, 94, 102-105.

Fisher M., Schneider M., Pegler C., \& Napolitano B. (1991). Eating attitudes, health-risk behaviors, self-esteem, and anxiety among adolescent females in a suburban high school. Journal of Adolescent Health, 12, 377-384.

Food and Nutrition Board, \& the Council on Foods and Nutrition. (1973). Diet and coronary heart disease. American Journal of Clinical Nutrition, 26, 53-54.

Fowler B. (1989). Relationship of body image perception and weight status to recent changes in weight status of the adolescent female. Adolescence, 24, 557-568.

Frank E., Winkleby M., Fortman S., Rockhill B., \& Farquhar J. (1993). Related knowledge and behavior and plasma cholesterol levels in youths during the 1980s. American Journal of Preventive Medicine, 9, 168-174.

Franzoi S., \& Shields S. (1984). Body esteem scale: multidimensional structure and sex differences in a college population. Journal of Personality Assessment, 48, 173-178.

Freedman R. (1984). Reflections on beauty as it relates to health in adolescent females. Women and Health, 9, 29-45.

French S., Story M., Downes B., Resnick M., \& Blum R. (1995). Frequent dieting among adolescents: psychosocial and health behavior correlates. American Journal of Public Health, 85, 695-701.

Garner D., Garfinkel P., \& Schwartz D. (1980). Cultural expectations of thinness in women. Psychological Reports, 47, 483-491.

Garrison R., Klesges L., \& Applegate W. (1996). Improving dietary patterns and physical activity levels among children and adolescents. Journal of the American Medical Association, 276 (July 17), 195.

Glanz K., Patterson R., Kristal C., \& Clemente D. (1994). Stages of change in adopting healthy diets: fat, fiber, and correlates of nutrient intake. Health Education Quarterly, 21, 499-519.

Glassner B. (1989). Fitness and the postmodern self. Journal of Health and Social Behavior, 30, 180-191.

Goldblatt P., Moore M., and Stunkard A. (1965). Social factors in obesity. Journal of the American Medical Association, 192,\#12, 1039- 1044. 
Grant C., \& Fodor I. (1986). Adolescent attitudes toward body image and anorexic behavior. Adolescence, 21, 269-281.

Gray S. (1977). Social aspects of body image : perceptions of normalcy of weight and affect of college undergraduates. Perceptual and Motor Skills, 45, 1035-1040.

Greenfield D., Quinlan D., Harding P., Glass E., and Bliss A. Eating behavior in an adolescent population. International Journal of Eating Disorders, 6, 99- 111.

Guillen E., \& Barr S. (1994). Nutrition, dieting, and fitness messages in a magazine for adolescent women, 1970-1990. Journal of Adolescent Health, 15, 464-472.

Guy R., Rankin B., and Norvell M. (1980). The relation of sex role stereotyping to body image. Journal of Psychology, 105, 167- 173.

Hall S., Cousins J., \& Power T. (1991). Self-concept and perceptions of attractiveness and body size among Mexican-American mothers and daughters. International Journal of Obesity, 15, 567-575.

Harter S. (1988). Causes, correlates, and the functional role of global self-worth: a life-span perspective. In J. Kolligian \& R. Sternberg (Eds.), Perceptions of Competence and Incompetence Across the Life-Span. Connecticut: Yale University Press.

Ho C., Lempers J., \& Clark-Lempers D. (1995). Effects of economic hardship on adolescent self-esteem: a family mediation model. Adolescence, 30, 118-131.

International Food Information Council. (1993). Trends in teen nutrition. Food Insight, Jan/Feb 1993. http://ific info.health org/teentrnd.htm

Jannot M. (1996). Practicing what they preach. Hospitals and Health Networks, 70, Jan, 44.

Jeffery R., \& French S. (1996). Socioeconomic status and weight control practices among 20 to 45- year-old women. American Journal of Public Health, 86, 1005-1010.

Kelly J., Patten S., and Johannes A. (1982). Analysis of self-reported eating and related behaviors in an adolescent population. Nutritional Research, 2, 417-432.

Killen J., Taylor C., Hayward L., Wilson D., Haydel K., Hammer L., et al. (1993). An attempt to modify unhealthful eating attitudes and weight regulation practices of young adolescent girls. International Journal of Eating Disorders, 13, 369-384.

Lawrence D., \& Schank M. (1993). Health status, health perceptions, and health behaviors of young adult women. International Journal of Nursing Studies, 30, 527-535. 
Lowry R., Kann L., Collins J., \& Kolbe L. (1996). The effect of socioeconomic status on chronic disease risk behaviors among U.S. adolescents. Journal of the American Medical Association, 276 (September 11), 792-797.

Lundholm J., \& Littrell J. (1986). Desire for thinness among high school cheerleaders: relationship to disordered eating and weight control behaviors. Adolescence, 21, 573-579.

Mable H., Balance W., \& Galgan R. (1986). Body image distortion and dissatisfaction in university students. Perceptual and Motor Skills, 63, 907-911.

Magilvy J., McMahon M., Bachman M., Roark S., \& Evenson C. (1987). The health of teenagers: a focused ethnographic study. Public Health Nursing, 4, 35-42.

Mahoney E., \& Finch M. (1976). The dimensionality of body-cathexis. Journal of Consulting and Clinical Psychology, 92, 277-279.

Martin S., Housley K., \& McCoy H. (1988). Self-esteem of adolescent girls as related to weight. Perceptual and Motor Skills, 67, 879-884.

Mazur A. (1986). U. S. trends in feminine beauty and overadaptation. Sex Research, 22, 281-283.

McBride L. (1986). Teaching about body image: a technique for improving body satisfaction. Journal of School Health, 56, 76-77.

McCaleb A., \& Edgil A. (1994). Self-concept and self-care practices of healthy adolescents. Journal of Pediatric Nursing, 9, 233-238.

Miller L., Thomson W., \& Holcomb D. (1988). Health behavior and beliefs of students in traditional and health-oriented high schools. Journal of School Health, 58, 243-248.

Moreno A., and Thelen M. (1995). Eating behavior in junior high school females. Adolescence, 30, 171- 174.

Mueller C., Field T., Yando R., Harding J., Gonzalez K., Lasko D., \& Bendell D. (1995). Under-eating and over-eating concerns among adolescents. Journal of Child Psychology and Psychiatry, 36, 1019-1025.

Mullis A., Mullis R., \& Normandin D. (1992). Cross sectional and longitudinal comparisons of adolescent self-esteem. Adolescence, 27, 51-61.

Newell G., Hammig C., Jurich A., \& Johnson D. (1990). Self-concept as a factor in the quality of diets of adolescent girls. Adolescence, 30, 118-131. 
Nichter M., Ritenbaugh C., Nichter M., Vuckovic N., \& Aickin M. (1995). Dieting and "watching" behaviors among adolescent females: report of a multimethod study. Journal of Adolescent Health, 17, 153-162.

Perry C., Luepker R., Murray D. M., Kurth C., Mullis R., Crockett S., \& Jacobs D. (1988). Parent involvement with children's health promotion: the Minnesota Home Team. American Journal of Public Health, 78, 1156-1160.

Prokhorov A., Perry C., Kelder S., \& Klepp K. (1993). Lifestyle values of adolescents: results from the Minnesota Heart Health Youth Program. Adolescence, 28, 637-647.

Radius S., Dillman T.E., Becker M., Rosenstock I., \& Horvath W. (1980). Adolescent perspectives on health and illness. Adolescence, 15, 375-384.

Read M., Harveywebster M., \& Usinger-Lesquereux J. (1988). Adolescent compliance with dietary guidelines: health and education implications. Adolescence, 91, 567-575.

Rosenberg, M. (1965). Society and the adolescent self-image. Princeton University Press, Princeton, New Jersey.

Rozin D., \& Fallon A. (1988). Body image, attitudes to weight, and misperceptions of figure preferences of the opposite sex: a comparison of men and women in two generations. Journal of Abnormal Psychology, 97, 342-345.

Saltonstall R. (1993). Healthy bodies, social bodies: men's and women's concepts and practices of health in everyday life. Social Science and Medicine, 36, 7-14.

Sciacca J., Melby C., Hyner G., Brown A., and Femea P. (1991). Body Mass Index and perceived weight status in young adults. Journal of Community Health, 16, 159- 168.

Searles R., Terry R., \& Amos R. (1986). Nutrition knowledge and body-image satisfaction of female adolescents. Journal of Nutrition Education, 18, 123-127.

Secord P., \& Jourard S. (1953). The appraisal of body-cathexis: body cathexis and the self. Journal of Consulting and Clinical Psychology, 19, 343-347.

Serdula M., Collins E., Williamson D.F., Anda R.F., Pamuk E., \& Byers T.E. (1993). Weight control practices of U.S. adolescents and adults. Annals of Internal Medicine, 119, 667-671.

Shaw S., \& Kemeny L. (1989). Fitness promotion for adolescent girls: the impact and effectiveness of promotional material which emphasizes the slim ideal. Adolescence, 24, 677-687. 
Shontz F. (1974). Body image and its disorders. International Journal of Psychiatry in Medicine, 5, \#4, 461- 472.

Silverstein B., Perdue L., Peterson B., \& Kelly E. (1986a). The role of mass media in promoting a thin standard of bodily attractiveness for women. Sex Roles, 14, 519-532.

Silverstein B., Perdue L., Peterson B., Vogel L., and Fantini D. (1986b). Possible causes of the thin standard of bodily attractiveness for women. International Journal of Eating Disorders, 5, 907-916.

Storz N., \& Greene W. (1983). Body weight, body image, and perception of fad diets in adolescent girls. Journal of Nutrition Education, 15, 15-18.

Torres R., Fernandez F., \& Maceira D. (1995). Self-esteem and value of health as correlates of adolescent health behavior. Adolescence, 30, 403-412.

United States Department of Health, Education, \& Welfare. (1979). Healthy People. The Surgeon General's report on Health Promotion and Disease Prevention. HEW (PHS) Publication \# 79-55078.

Wendel G., \& Lester D. (1988). Body cathexis and self-esteem. Perceptual and Motor Skills, 67, 538 .

West Virginia Department of Health and Human Resources. (1996). West Virginia 1996 Behavioral Risk Factor Survey. Office of Epidemiology and Health Promotion, Bureau of Public Health, Charleston, West Virginia.

Whitney E., and Rolfes S. (1993). Understanding Nutrition. $\left(6^{\text {th }}\right.$ ed.). (p 255- 256). Minneapolis/ St. Paul: West Publishing Company.

Witte D., Skinner J., \& Carruth B. (1991). Relationship of self-concept to nutrient intake and eating patterns in young women. Journal of the American Dietetic Association, 1068-1073.

Wooley O., \& Roll S. (1991). Color-a-person body dissatisfaction test: stability, internal consistency, validity, and factor structure. Journal of Personality Assessment, 56, 395-413.

Zakin D., Blyth D., \& Simmons R. (1984). Physical attractiveness as a mediator of the impact of early pubertal changes for girls. Journal of Youth and Adolescence, 13, 439- 450. 


\section{APPENDICES}

Appendix A

Appendix B

Appendix C

Appendix D 
Appendix A

Survey Questionnaire 


\section{QUESTIONNAIRE}

$\#$

(Please leave blank)

This questionnaire is anonymous. If you choose to fill it out, please be as honest as you can in your answers. It asks about your body weight and size, eating habits, how you feel about yourself, and general information about your family. If answering these kinds of questions is uncomfortable for you, you may choose not to fill out the questionnaire.

1. What is your age? years.

2. What school are you are currently attending?

3. What is your major or field of study?

4. How many years of junior and senior high school $\left(7^{\text {th }}\right.$ to $12^{\text {th }}$ grades $)$ did you attend in West Virginia schools? years.

5. Please check as many as apply: Are you __ white __ black __ Hispanic Asian _ Native American. Other( please specify):

6. Marital status: _ _ single _ _ married _ _ divorced

7. Who provides your current source of income? Please check as many as apply: __ yourself (through a job) _your family ( parents or other family members) __your spouse _ _ financial aid food stamps or other government program. Other( please specify):

8. Your family's average income per year: please put a check by the correct selection. If you are not certain, please make your best guess:__ under $\$ 10,000 \_$_ $\$ 10,000-19,000 \_\$ 20,000-29,000$ _ $\$ 30,000-39,000 \_\$ 40,000-49,000 \_\$ 50,000-59,000 \_$_ $\$ 60,000$ or more

9. Highest grade completed by mother: __ less than $12^{\text {th }}$ grade __ _ high school graduate 1 or more yrs college __ 1 or more years vocational school___college graduate vocational school graduate __ 1 or more years postgraduate school 
10. Highest grade completed by father: less than $12^{\text {th }}$ grade _ _ high school graduate 1 or more years college __ 1 or more years vocational school __ college graduate vocational school graduate __ 1 or more years postgraduate school

11. Are you an active member of a church, temple, or religious group? _ Y Yes _ _ No 12. Current Weight Height

13. Are you satisfied with your current weight?

_Y Yes, I am satisfied. No, I would prefer to weigh pounds.

Don't know/have no opinion.

14. Are you satisfied with your current pants size?

_ Yes, I am satisfied with my size.

_ No, I would prefer to be: ___smaller___ larger

$$
\text { by _ـ } 1 \text { size _ } 2 \text { sizes _ } 3 \text { sizes or more }
$$

_Don't know/ No opinion

15. How important is it to you to be at your preferred weight and/or size?

Please circle the number that best describes your answer:

very unimportant unimportant no opinion important very important

$\begin{array}{lllll}1 & 2 & 3 & 4 & 5\end{array}$

If you circled " 1 ," " 2 ," or “ 3 ," please go to question \# 17. Otherwise, continue with question \# 16.

16. Why do you feel it is important to be at your preferred weight or size?

You may select one or more answers. If you select more than one, please rank your answers in order of importance (1= most important, $2=$ next most important, $3=$ less important, $4=$ least important).

a. to look and feel more attractive to yourself or others

b. to be better liked and accepted by other people

c. to be healthy (having enough energy and being free from illness)

d. to be in good physical shape (having endurance and strength)

Other reason (please explain and rank importance): 
17. Please select one answer. How would you describe yourself at your current weight or size?

a. heavy
b. on the heavy side of average
c. average
d. on the thin side of average
e. thin
f. don't know

18. How often do you eat fast foods or "junk" foods?
never rarely occasionally
frequently
all the time
don't know

19. Do you feel that people who eat fast foods and "junk" foods are more likely to gain weight than people who don't eat these foods? __ Yes___ _ _ _ _ _ Don't know/ No opinion

20. How frequently do you exercise, or participate in sports or physical activities? (walking, gardening, etc) less than once a month once a month once every 1 or 2 weeks

2 to 3 times a week every day

21. How frequently do you eat regular, nutritionally balanced meals?

never rarely occasionally frequently all the time don't know

22. Please select one of the following choices: Would you describe yourself as someone who

a. diets (restricts food intake regularly or occasionally)

b. uses a combination of dieting and watching what you eat

c. watches what you eat (does not diet)

d. neither diets nor watches what you eat

\section{If you chose "a" or "b," please continue with question \# 23. If you chose "c" please skip to question \# 26. If you chose "d," please skip to question \# 29.}

23. Please choose the best answer: How often do you diet (restrict food intake)?

1 to 3 times a year once or twice a month once or twice a week every day 
24. Why do you usually diet?

You may select one or more answers. If you select more than one, please rank your answers in order of importance (1= most important, $2=$ next most important, $3=$ less important, $4=$ least important $)$.

a. lose weight

b. gain weight

c. maintain your weight

d. maintain or improve your health

Other reason (please explain and rank importance):

25. Please check all the dieting strategies that you usually use or prefer to use when you diet:

a. eat foods with fewer calories

b. eat more fruit and vegetables

c. eat regular balanced meals

d. eat fewer meals

e. skip meals when hungry

f. fast (stop eating for 1 day or more)

g. go on a weight watcher type diet plan

h.. use water pills, laxatives, or diet pills

i. go on a crash diet (eat only 1 or 2 kinds of food, or go on a very low calorie diet )

Other method (please describe):

26. Please choose the best answer: How often do you watch what you eat?

1 to 3 times a year __ once or twice a month _ _ once or twice a week _ _ every day 
27. Why do you usually watch what you eat?

You may select one or more answers. If you select more than one, please rank your answers in order of importance ( $1=$ most important, $2=$ next most important, $3=$ less important, $4=$ least important).

a. lose weight

b. gain weight

c. maintain your weight

d. maintain or improve your health

Other reason (please specify and rank importance):

28. Please check all the strategies that you usually use or prefer to use when you watch what you eat:

a. eat more fruit and vegetables

b. avoid junk food

c. eat regularly balanced meals

d. eat lower calorie foods e. eat lower fat foods

f. eat the same but notice

g. cut out snacks

h. exercise regularly

Other method (please specify):

29. How would you describe your current state of health?
excellent average
below average
poor
don't know/no opinion

30. Please check all the following statements about health, diet, and lifestyle that apply to you:

a. I am actively involved in following a healthy diet and lifestyle because health is important to me.

b. I think it is a good idea to follow a healthy diet and lifestyle, but it's not a priority for me (I don't go out of my way to do it).

c. I don't think that following a healthy diet and lifestyle would make an important difference in my health.

_ d. I am trying to do a better job of following a healthy diet and lifestyle because I do think health is important.

e. I don't know much, or I don't think much about my health or my diet and lifestyle.

f. It isn't important to me to follow a healthy diet and lifestyle right now, but it probably will be when I'm older. Comments: 


\section{If you answered that you are a person who diets and/or watches what you eat, please skip to question \# 32 (next page). If you answered that you do not diet or watch what you eat, please answer question \# 31 (next).}

31. If you answered that you rarely or never diet, or rarely or never watch what you eat, please check all the following statements that apply to you:

a. I am satisfied with my weight and size so I don't need to diet or watch what I eat in order to maintain them.

b. I exercise when I want to change my weight or size instead of changing how I eat.

c. I am not satisfied with my weight or size but I don't feel that I can change them.

d. My weight and size are not high priorities for me.

e. I already follow a healthy diet and have good nutritional habits, so I don't need to diet or watch what I eat.

f. I think my diet could use improvement, but it takes too much energy to diet or watch what I eat.

g. I don't know enough about nutrition to know whether I should diet or watch what I eat.

h. I am not satisfied with my nutritional habits but don't feel I can change them.

i. Nutrition is not a high priority for me.

Other reason (please state): 
32. Using the following scale, please write the number that best describes your feelings about yourself on the line next to each question.

$\begin{array}{cccc}\text { Strongly disagree } & \text { Disagree } & \text { Agree } & \text { Strongly Agree } \\ 1 & 2 & 3 & 4\end{array}$

I feel I am a person of worth, at least on an equal basis with others.

I feel I have a number of good qualities.

All in all, I am inclined to feel that I am a failure.

_ I am able to do things as well as most other people.

I I feel I do not have much to be proud of.

_ I take a positive attitude toward myself.

_ On the whole, I am satisfied with myself.

_ I wish I could have more respect for myself.

_ I certainly feel useless at times.

At times I think I am no good at all.

\section{Thank you for your participation!}


Appendix B

Survey Questionnaire, coded 


\section{CODED QUESTIONNAIRE}

1. What is your age? $18 \mathrm{yrs}=\underline{1} \quad 19 \mathrm{yrs}=\underline{2}$

(variable: $\underline{\text { Age, }}$ Methods, p.35)

2. What school are you currently attending?

1= Davis and Elkins College $\quad 7=$ United Technical Center

2= Fairmont State College $\quad 8=$ Lincoln High School

3= Bridgeport High School 9= Wheeling Jesuit university

4= Robert C. Byrd High School 10= West Virginia University

5= Doddridge High School 11= Salem-Teikyo University

6= Liberty High School

(variable: $\underline{\text { School, }}$ Methods p.36)

3. What is your major field of study? vocational $=\underline{1}$ undeclared $=\underline{2}$ academic $=\underline{3}$ health related $=\underline{4}$

4. How many years of junior and senior high school ( $7^{\text {th }}$ to $12^{\text {th }}$ grades $)$ did you attend in West

Virginia schools $? \quad 4$ years or more $=\underline{2}$ (resident) less than 4 years $=\underline{1}$ (non resident)

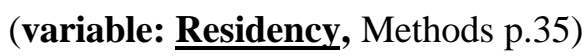

5. Please check as many as apply:

Are you : 1 white 2 black 3 Hispanic $\underline{4}$ Asian $\underline{5}$ Native American

6 Other $(7$ mixed $)$

(variable: Race, Methods p.35)

6. Marital status: $\underline{1}$ single $\underline{2}$ married $\underline{3}$ divorced

7. Who provides your current source of income? Please check as many as apply:

_yourself __ your family ( parents or other family members) _ _ your spouse

_ financial aid __ food stamps or other government program. Other( please specify)__

Variable coding:

choices checked $=2$ (yes). $\quad$ choices not checked $=1$ (no). 
8. Your family's average income per year: please put a check by the correct selection.

If you are not certain, please make your best guess: $\quad \underline{1}$ under $\$ 10,000 \quad \underline{2} \$ 10,000-19,000$

$\underline{3} \$ 20,000-29,000 \underline{4} \$ 30,000-39,000 \quad \underline{5} \$ 40,000-49,000 \quad \underline{6} \$ 50,000-59,000$

$7 \$ 60,000$ or more

(variable: Family Income, Methods p.29)

9. Highest grade completed by mother: 1 less than $12^{\text {th }}$ grade $\quad 2$ high school graduate

$\underline{3} 1$ or more years vocational school $\underline{4}$ vocational school graduate $\underline{5}$ one or more years college

$\underline{6}$ college graduate $\underline{7} 1$ or more years postgraduate school

(variable: Mother's Education, Methods p.30)

10. Highest grade completed by father: 1 less than $12^{\text {th }}$ grade $\quad 2$ high school graduate

$\underline{3} 1$ or more years vocational school $\underline{4}$ vocational school graduate $\underline{5}$ one or more years college

$\underline{6}$ college graduate $\underline{7} 1$ or more years postgraduate school

(variable: Father's Education, Methods p.30)

11. Are you an active member of a church, temple, or religious group?

$\underline{2}$ Yes $\underline{1}$ No

(variable: Religiosity, Methods p.30)

12. Current Weight_________ Heinds) Height

Body Mass Index $(\mathrm{BMI})=$ weight in kilograms $\div$ height $^{2}$ in meters

13. Are you satisfied with your current weight?

$\underline{2}$ Yes $\underline{1}$ No, my preferred weight is ___ pounds $\quad \underline{0}$ Don't know/no opinion Variable coding:

a. Desired BMI determined from height (question 12) and desired weight (question 13).

BMI $<20.4=$ desire for thinness $\quad$ BMI $\geq 20.4=$ lack of desire for thinness

(variable: Comparison Groups, Methods p.31) 
b. weight satisfaction $=2$ weight dissatisfaction $=1$

(variable: Body Weight Satisfaction, Methods p.27)

c. desired weight loss $=$ current weight - desired weight.

weight loss desired: $0 \mathrm{lb} .=1 \quad 1$ to $3 \mathrm{lb} .=2 \quad 4$ to $6 \mathrm{lb} .=3 \quad 7$ to $10 \mathrm{lb} .=4 \quad 11$ to $14 \mathrm{lb} .=5$

15 to $20 \mathrm{lb} .=6 \quad 21+\mathrm{lb} .=7$

(variable : Weight Loss Group, Methods p.34)

14. Are you satisfied with your current pants size?

$\underline{2}$ Yes $\quad \underline{1}$ No $\quad \underline{0}$ Don't know/ No opinion

I would prefer to be __smaller__ _ larger

By $\quad 11$ size $\quad \underline{2} 2$ sizes $\quad \underline{3} 3$ or more sizes (variable: $\underline{\text { Size Loss Group, Methods p.35) }}$

Variable coding:

size satisfaction $=2$ size dissatisfaction $=1$

(variable: Size Satisfaction Score, Methods p.34)

15. How important is it to you to be at your preferred weight and/or size?

Please circle the number that best describes your answer:

very unimportant unimportant no opinion important very important

$\begin{array}{lllll}1 & 2 & 3 & 4 & 5\end{array}$

Variable coding:

$1=1 \quad 2=2 \quad 3=3 \quad 4=4 \quad 5=5$

(variable: Importance Score, Methods p.34)

16. Why do you feel it is important to be at your preferred weight or size?

You may select one or more answers. If you select more than one, please rank your answers in order of importance (1= most important, $2=$ next most important, $3=$ less important, $4=$ least important $)$ a. to look and feel more attractive to yourself or others

b. to be better liked and accepted by other people

c. to be healthy (having enough energy and being free from illness)

d. to be in good physical shape (having endurance and strength) 
Variable coding:

$1=4 \quad 2=3 \quad 3=2 \quad 4=1$. Only choices ranked 4 and 3 were counted.

The following groups were defined based on choices ranked most important:

$1=$ those who chose only appearance factors as important (choices a and/or b)

$2=$ those who chose only health as important (choices $\mathrm{c}$ and/or d)

$3=$ those who chose a mix of appearance and health factors as important (choices a or b and c or d)

$4=$ those who chose no factors because body image was not important (as defined by selecting a " 1 ,"

"2," or " 3 " in question 15)

(variable: Body Image Group, Methods p.33)

17. Please select one answer. How would you describe yourself at your current weight or size?
a. 1 heavy
b. 2 on the heavy side of average
c. 3 average
d. 4 on the thin side of average
e. $\underline{5}$ thin
f. $\underline{0}$ don't know

Variable coding:

Actual BMI range was coded as follows: BMI of 16 to $18.9=1$ (thin), BMI of 19 to $20.3=2$

(thinner than average) BMI of 20.4 to $22.9=3$ (average) $\quad$ BMI of 23 to $25.9=4$ (heavier than

average) $\quad$ BMI of 26 or more $=5$ (heavy)

Subjects' responses were compared to actual BMI range and coded as follows:

underestimate $=1 \quad$ accurate estimate $=2 \quad$ overestimate $=3$

(variable: Weight Perception Accuracy, Methods p.27) 
18. How often do you eat "junk" or fast foods? $\underline{0}$ never $\quad 1$ rarely $\underline{2}$ occasionally $\underline{3}$ frequently

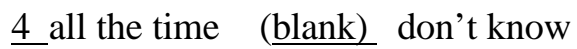

(variable: Junk Food Frequency, Methods p.38)

19. Do you feel that people who eat junk and fast foods are more likely to gain weight than people who don't eat these foods? $\quad \underline{2}$ Yes $\quad \underline{1}$ No $\quad \underline{0}$ Don't know/ No opinion

20. How frequently do you usually exercise or participate in sports?

$\underline{0}$ less than once a month (never) $\underline{1}$ once a month (rarely) $\underline{4}$ once every 1 or 2 weeks (occas.)

$\underline{10}$ two to 3 times a week (frequently) $\underline{30}$ every day (always)

Variable coding:

The above coded numbers were based on frequency per month.

In addition, this variable was coded on a scale of never to always such that : never $=0$ rarely $=1$

occasionally $=2$ frequently $=3$ always $=4 . \quad$ (variable: Exercise Frequency, Methods p.39)

21. How frequently do you eat regular, nutritionally balanced meals?

$\underline{0}$ never $\underline{1}$ rarely $\underline{2}$ occasionally $\underline{3}$ frequently $\underline{4}$ all the time $(\underline{b l a n k})$ don't know

(variable: Regular Meals, Methods p.39)

22. Please select one of the following choices:

Would you describe yourself as someone who

a.1 Diets (restricts food intake regularly or occasionally)

b. 2 Uses a combination of dieting and watching what you eat

c. 3 Watches what you eat (does not diet)

d. 4 Neither diets nor watches what you eat

(variable: Food Management Group, Methods p.30)

23. How often do you diet? $\underline{0.25}$ one to 3 times a year (rarely ) $\underline{2}$ once or twice a month (occas.)

$\underline{4}$ once or twice a week (frequently) $\underline{30}$ every day (always) 
Variable coding:

The above coded numbers were based on frequency per month. In addition, this variable was coded on a scale of never to always such that : rarely $=1$, occasionally $=2$, frequently $=3$, always $=4$

(variable: Diet frequency, Methods p.38)

24. Why do you usually diet? You may select one or more answers. If you select more than one, please rank your answers in order of importance:

( $1=$ most important, $2=$ next most important, $3=$ less important, $4=$ least important $)$
a. lose weight
b. gain weight.
c. maintain your weight
d. maintain or improve your health

Variable coding:

$1=4 \quad 2=3 \quad 3=2 \quad 4=1$. Only choices ranked " 4 " and "3" were counted.

(variable: Diet Motivation, Methods p.37)

25. Please check all the dieting strategies listed below that you usually use or prefer to use when you diet:
a. eat foods with fewer calories
j. avoid junk food
b. eat more fruit and vegetables
k. eat less food at meals
c. eat regularly balanced meals
1. cut out snacking
d. eat fewer meals
m. intentionally vomit after meals
e. skip meals when hungry
n. go on an all liquid diet
f. fast (stop eating for 1 day or more)
o. exercise regularly
g. go on a weight watcher type diet plan
p. exercise intensively
h. use water pills, laxatives, or diet pills
i. go on a crash diet (eat only 1 or 2 kinds of food or go on a very low calorie diet) 
Variable coding:

$\underline{2}=$ yes $($ checked $) \quad \underline{1}=$ no $($ not checked $)$
$\mathrm{a}, \mathrm{b}, \mathrm{c}, \mathrm{g}, \mathrm{j}, \mathrm{k}, \mathrm{l}$, and $\mathrm{o}=$ healthy strategies
$\mathrm{d}, \mathrm{e}, \mathrm{f}, \mathrm{h}, \mathrm{i}, \mathrm{m}$, and $\mathrm{n}=$ unhealthy strategies

(variable: Diet Behavior, Methods p. 36)

26. How often do you watch what you eat?

$\underline{0.25}$ one to 3 times a year (rarely ) $\underline{2}$ once or twice a month (occasionally)

$\underline{4}$ once or twice a week (frequently) $\underline{30}$ every day (always)

Variable coding:

The above coded numbers were based on frequency per month. In addition, this variable was coded on a scale of rarely to always such that : rarely $=1$, occasionally $=2$, frequently $=3$, always $=4$

(variable: Watch Frequency, Methods p.38).

27. Why do you usually watch what you eat? You may select one or more answers. If you select more than one, please rank your answers in order of importance:

(1= most important, $2=$ next most important, $3=$ less important, $4=$ least important $)$
a. lose weight
b. gain weight
c. maintain your weight
d. maintain or improve your health.

Variable coding:

$1=4 \quad 2=3 \quad 3=2 \quad 4=1$. Only choices ranked 4 and 3 were counted.

(variable: Watch Motivation, Methods p.37) 
28. Please check all the strategies listed below that you usually use or prefer to use when you watch what you eat:
a. eat more fruit and vegetables
e. eat lower fat foods
b. avoid junk food
f. eat the same but notice
c. eat regularly balanced meals
g. cut out snacks
d. eat lower calorie foods
h. exercise regularly

Variable coding:

$\underline{2}=$ yes $($ checked $) \quad \underline{1}=$ no $($ not checked $)$

(variable: Watching Behavior, Methods p.37)

29. How would you describe your current state of health?

$\underline{4}$ excellent $\underline{3}$ average $\underline{2}$ below average $\underline{1}$ poor $\underline{0}$ don't know/ no opinion

30. Please check all the following statements about health, diet, and lifestyle that apply to you:

a. I am actively involved in following a healthy diet and lifestyle because health is important to me.

b. I think it is a good idea to follow a healthy diet and lifestyle, but it's not a priority for me (I don't go out of my way to do it).

c. I don't think that following a healthy diet and lifestyle would make an important difference in my health.

d. I am trying to do a better job of following a healthy diet and lifestyle because I do think health important.

e. I don't know much, or I don't think much about my health or my diet and lifestyle.

f. It isn't important to me to follow a healthy diet and lifestyle right now, but it probably will be when I'm older.

\section{Variable coding:}

$\underline{2}=$ yes $($ checked $) \underline{1}=$ no $($ not checked $)$

Desire for health $=\mathrm{a}, \mathrm{d}$, ad, acd, or ade.

Lack of desire for health $=\mathrm{b}$ alone or in combination with other choices, or $\mathrm{c}, \mathrm{e}, \mathrm{f}$. 
31. If you answered that you rarely or never diet, or rarely or never watch what you eat, please chec all the following statements that apply to you:

a. I am satisfied with my weight and size and don't need to diet or watch what I eat in order to maintain these.

b. I exercise when I want to change my weight or size instead of changing how I eat

c. I am not satisfied with my weight or size but I don't feel that I can change them.

d. My weight and size are not high priorities for me.

e. I already follow a healthy diet and have good nutritional habits, so I don't need to diet or watch what I eat.

f. I think my diet could use improvement, but it is easier in general not to diet or watch what I eat.

g. I don't know enough about nutrition to know whether I should diet or watch what I eat.

h. I am not satisfied with my nutritional habits but don't feel I can change them.

i. Nutrition is not a high priority for me.

j. Other reason (please state):

Variable coding:

$\underline{2}=$ yes $($ checked $) \quad \underline{1}=$ no $($ not checked $)$ 
32. Using the following scale, please write the number that best describes your feelings about yourself on the line next to each question.

$\begin{array}{cccc}\text { Strongly disagree } & \text { Disagree } & \text { Agree } & \text { Strongly Agree } \\ 1 & 2 & 3 & 4\end{array}$

$+1 . \quad$ I feel I am a person of worth, at least on an equal basis with others.

+2 ___ I feel I have a number of good qualities.

$+3 . \quad$ All in all, I am inclined to feel that I am a failure.

+ 4.__ I am able to do things as well as most other people.

- 5.__ I feel I do not have much to be proud of.

$+6 . \quad$ I take a positive attitude toward myself.

+7 .__ On the whole, I am satisfied with myself.

- 8.__ I wish I could have more respect for myself.

- 9.__ I certainly feel useless at times.

- 10.___ At times I think I am no good at all.

Variable coding:

For questions $5,8,9$, and 10 , scoring was reversed so that: $1=4,2=3,3=2,4=1$. Self-esteem scores were then converted into discrete categories as follows: score of 14 to $19=1, \quad$ score of 20 to $24=2, \quad$ score of 25 to $29=3, \quad$ score of 30 to $34=4$, score of 35 to $40=5$. (variable: Self-esteem Group, Methods p. 28) 
Appendix C

Institutional Review Board Approval Letter Approved Letter of Introduction to Students 


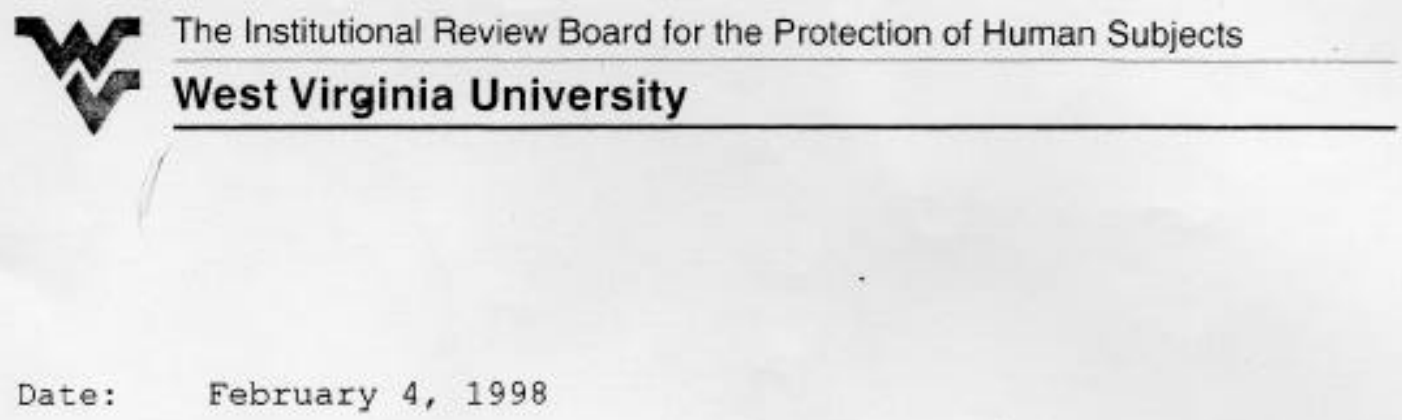

ME MOR A N D U M

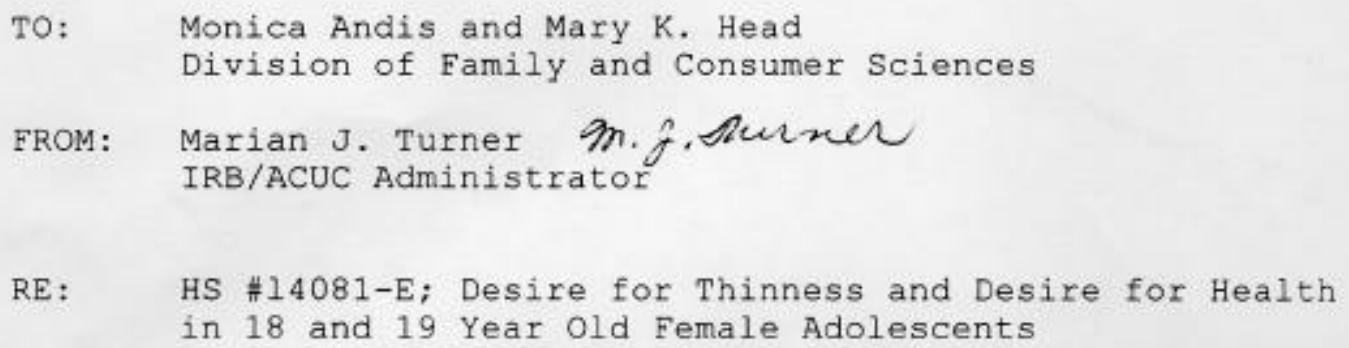

$\mathrm{MJT} / \mathrm{baw}$ 


\section{Application for Exemption}

Gtenntect Hat

$$
\begin{aligned}
& 886 \text { Chestrut Redegeth. } \\
& \$ 14881
\end{aligned}
$$

You must receive approval from the IRB staff prior to beginning the research described below. Please type all responses and submit this form with original signatures.

1. Title of study: Desire for thinness and desire for health in 18 and 19 year femal adelescents

\begin{tabular}{|c|c|c|c|c|}
\hline Name & Signature & Dept./College & Address & Tel.No. \\
\hline Monica Andis & yeaso cuats & $\begin{array}{l}\text { Agriculture and } \\
\text { Forestry }\end{array}$ & $\begin{array}{l}1120 \text { Denver Ave } \\
\text { Morgantown }\end{array}$ & $296-3216$ \\
\hline Mary K. Head & see lack & same & 702 Allen Hall & $293-3402$ \\
\hline
\end{tabular}

2. Investigators (list all investigators, principal investigator first; attach additional sheets if necessary):

3. Estimated period of human subject involvement: Starting date: Feb 6, 1998 Ending date: May9, 1998

4. Reason for conducting research:

$\square$ Professional $\square$ Dissertation XंThesis $\square$ Class Assignment $\square$ Other: specify

5. Source of funding (if applicable):

6. This research involves (check all that apply):

— a. collection or study of existing data, documents, records or specimens

_ b. normal educational practices conducted in established or commonly accepted educational settings

$\checkmark$ c. educational tests (cognitive, diagnostic, aptitude, achievement)

- d. observation of public behavior

$\perp$ e. surveys or interviews:
$\checkmark$ mail
$\square$ telephone
person-to-person

_ f. any possibility of identifying a subject (discuss in cover letter)

- g. the possibility that the subject's responses or conduct (if they became public) may place the subject at risk of criminal or civil liability or be damaging to the subject's financial standing or employability

—h. sensitive aspects of personal behavior (for example: illegal conduct, drug use, sexual behavior or use of alcohol)

_i. investigator's participation in activities being observed

- j. only surveys or interviews of elected or appointed public officials or ca

_k. audiotaping

- l. children under age 18 (see Chapter II of the Guidelines) Note: Interviews and surveys with children are never exempt.

7. Goal of research

To survey the incidence of desire for thinness and desire for health, and the different dietary behaviors that may accompany these desires in adolescent girls in north-central west virginia. The study will also assess some of the varlables chat may be related to these desires and dietary behaviors, specifically: self-esteem, socioeconomic status, and body image satisfaction. 


\section{Division of Family and Consumer Sciences}

West Virginia University

College of Agriculture, Forestry and Consumer Sciences

To: Students

From: Monica Andis, graduate student

I am currently conducting a research project in partial fulfillment

of my Master's degree in Family and Consumer Sciences at West Virginia

University. My research is about body image and dietary behavior of older

adolescent girls. If you are a girl of 18 or 19 years of age, I am asking for

your participation in my study by answering a questionnaire. The questionnaire will take approximately 10 to 20 minutes to complete. It is anonymous, so your name will not be asked for or needed at any time. PLEASE DO NOT PUT YOUR NAME ANYWHERE ON THE QUESTIONNAIRE!!

Your participation in this study is entirely voluntary. You do not have to participate if you do not want to do so. You will not suffer any penalty, loss of benefits, change in grade or class standing if you choose not to participate, or if you do not answer every question.

If you do choose to answer the questionnaire, please drop it in the collection box when you are finished, or mail it back to me in the enclosed envelope. Thanks for your help!

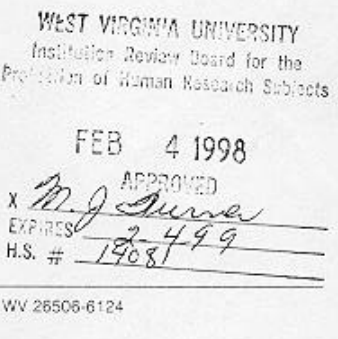




\section{Appendix D \\ Permission Form Letters \\ Permission Letters From Surveyed Institutions}


Monica Andis

1120 Denver Avenue

Morgantown, West Virginia 26505

(304) 296-3216

February 11, 1998

Dear

I am a graduate student in the Family and Consumer Sciences Department of West Virginia University and am currently conducting a research project on body image and dietary behaviors of eighteen and nineteen year old girls. I have developed a survey questionnaire to give to students in order to collect the information I need. I am seeking permission from your institution to distribute the questionnaire on campus to some of your students.

The questionnaire is voluntary and anonymous and takes about ten minutes to complete. In order to distribute the questionnaire, I plan to contact teachers of introductory freshman courses such as English, mathematics, or psychology, and ask for five minutes of their class time to introduce the questionnaires. I will either provide a collection box or self addressed stamped envelopes so that participants can return the forms to me. I will not be present while the forms are distributed, nor while participants fill out and return the forms. Every participant will receive a copy of the enclosed letter which explains that participation is voluntary and anonymous. I will also state this verbally when I introduce myself and the questionnaire. I will be the only investigator having direct contact with students.

Enclosed is the questionnaire, the explanatory letter for students, and copies of the application and approval forms that are currently on file with the West Virginia University Institutional Review Board.

I would appreciate a reply at your earliest convenience so that I may complete my project in a timely fashion.

Sincerely, 
Monica Andis

1120 Denver Avenue

Morgantown, West Virginia 26505

(304) 296-3216

February 11, 1998

Dear

I am a graduate student in the Family and Consumer Sciences Department of West Virginia University and am currently conducting a research project on body image and dietary behaviors of eighteen and nineteen year old girls. I have developed a survey questionnaire to give to students in order to collect the information I need. I am seeking your permission to distribute the questionnaire to some of the students enrolled in your technical education school.

If you approve, I will contact the principal of the school to obtain his or her approval, and then contact individual teachers to ask for five minutes of their class time in which to introduce and explain the questionnaire. The questionnaire is voluntary and anonymous and should take approximately ten minutes to complete. I will either provide a collection box or self addressed stamped envelopes so that participants can return the forms to me at their convenience. I will not be present while the forms are distributed, nor while participants fill out and return the forms. Every participant will receive a copy of the enclosed letter which explains that participation is voluntary and anonymous. I will also state this verbally when I introduce myself and the questionnaire. I will be the only investigator having direct contact with students.

Enclosed is the questionnaire, the explanatory letter for students, and copies of the application and approval forms that are currently on file with the West Virginia University Institutional Review Board.

I would appreciate a reply at your earliest convenience so that I may complete my project in a timely fashion.

Sincerely, 


\title{
HARRISON COUNTY SCHOOLS
}

\author{
408 E. B. Saunders Way \\ BOARD OF EDUCATION \\ Post Office Box 1370 \\ Clarksburg, West Virginia 26302-1370 \\ (304) $624-3325$ \\ PETER J. CONLEY, President \\ A. GARRETT SNYDER, Vice President \\ WILSON CURREY \\ DOUG GRAY
}

ROBERT E. KITTLE

Superimtendent

March 2, 1998

Ms. Monica Andis

1120 Denver Avenue

ivorgantown, WV zó505

Dear Ms. Andis,

After a review of your letter of February 24 which contained your assurance that a copy of your thesis will be forwarded to this office upon completion, I am happy to grant permission for you to conduct your research project at United Technical Center. Please remember, however, that permission must also be obtained from Joan Smith, Director of United Technical Center.

You may contact her at (304) 624-3280.

Please let me know if there is any way that my office might be of assistance, and best wishes for success with your research project.

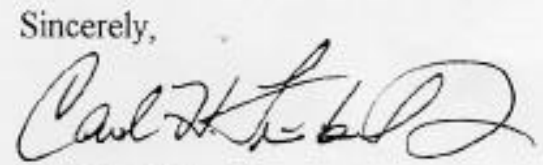

Carl H. Friebel, Jr.

Administrative Assistant

Planning, Research \& Evaluation:

cc: Ms. Joan Smith

CHF/tih 


\section{Doddridge County Schools \\ 104 Sistersville Pike \\ West Union, West Virginia 26456 \\ Telephone: (304) $873-2300$ or $782-1167$ \\ Fax: (304) 873-2210}

February 23, 1998

Monica Andis

1120 Denver Avenue

Morgantown, WV 26505

Dear Ms. Andis:

Please accept this letter as approval to conduct your research. However, you will need to receive approval from Ms. Joan Smith, Director of United Technical Center in Clarksburg, the technical school where Doddridge County students attend.

If you have questions please contact Ms. Smith at 624-3281.

Sincerely,

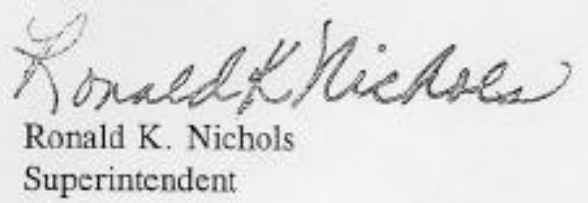

RKN/mek 


\section{n}

\section{Davis \& Elkins College}

Vice President \&

Dean of the Faculty

Monica Andis

1120 Denver Avenue

Morgantown, WV 26505

Dear Ms. Andis,

Your research project has been approved and you have my permission to conduct the project in the classrooms at Davis \& Elkins College.

If I can be of further assistance, please let me know.

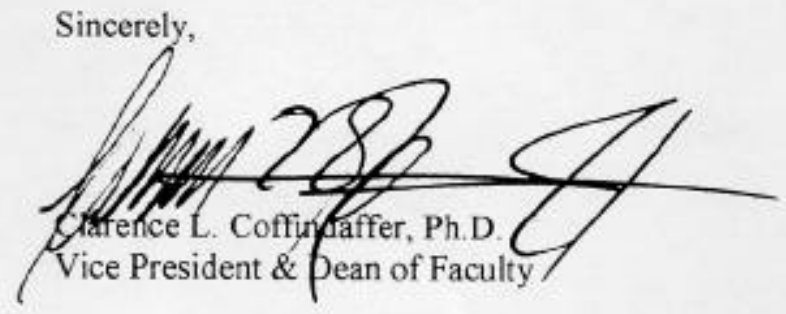

$\mathrm{CLC} / \mathrm{skw}$ 


\section{mering \\ FAIRMONT \\ 5 TATE COLLEOE}

Office of the Ditision

of Suctial Scirnore

February 26, 1998

Ms. Monica Andis

1120 Denver Avenue

Morgantown, WV 26505

Dear Ms Andis:

I circulated your research proposal to the members of the Fairmont State College Human Subjects Review Board. None of them expressed any concern about your proposal. You have the approval of the Review Board to conduct your survey at Fairmont State College

You will, of course, have to obtain permission from the instructors of the courses you wish to survey. Please inform them that you have approval from the Review Board.

Good luck with your research.

Sincerely,

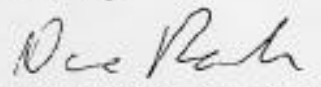

Dave Rausch, Ph.D., Chair

Human Subjects Review Board

cc: file 


\section{All \\ WHEELING JESUIT UNIVERSITY}

Institutional Review Board for the Protection of Human Subjects

$304-243-2319$

February 27, 1998

Ms. Monica Andis

1120 Denver Avenue

Morgantown, WV 26505

Re: Study of Desire for Thinness and Desire for Health in 10 and 19-Year Old Fomale

Adolescents

Dear Ms. Andis:

The Institutional Review Board for the Protection of Human Subjects has reviewed and approved the application for Exemption for your research named above. Please indicate this approval to your participants at Wheeling Jesuit University.

This exemption approval will remain in effect on the condition that the research is carried out exactly as described in the Application.

Best wishes for success in your research.

Sincerely,

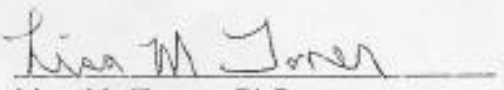

Lisa M. Toner, PhD.

Chair, IRB 


\section{SALEM - TEIKYO UNIVERSITY}

Salem, West Virginia 26426-500

MEMORANDUM

TO: $\quad$ Monica Andis and Mary K. Head

Division of Family and Consumer Sciences

FROM Wayne H. England, Ph.D, Vice President for Academic Affairs and Provost 142

DATE: $\quad$ April 2, 1998

SUBJECT: Graduate Research Project

I would like to confirm our conversation that you may perform the research project titled Desire for Health in 18 and 19 Year Old Female Adolescents. This proposal has been approved by the Committee on Safeguards in Human Research and has also been reviewed by our Director of our Public/Community Heatlh program, Dr. Charlotte Guynes.

bblm 


\section{ABSTRACT \\ DESIRE FOR THINNESS AND DESIRE FOR HEALTH IN EIGHTEEN AND NINETEEN YEAR OLD FEMALE ADOLESCENTS \\ By Monica Andis}

Desire for thinness and desire for health were surveyed among eighteen and nineteen year old female adolescents in north-central West Virginia to determine the incidence of these motivations within this population and the relationship of these motivations to unnecessary weight loss concerns, and healthy and unhealthy dieting behaviors. Factors previously shown to be associated with desire for thinness or health include body image satisfaction, self-esteem, socioeconomic status, religiosity, and food management behavior. Variables derived from these factors were examined for their ability to predict desire for thinness and health in subjects.

Self-reported heights, weights, preferred weights, and other data were collected via survey questionnaires. Desire for thinness was defined as desiring a Body Mass Index of less than 20.4. Desire for health was determined from answers to a survey question asking about the importance of following a healthy diet and lifestyle. Food management behavior was represented by the variable of food management group, defined according to whether subjects dieted only, "watched what they ate" only, both dieted and "watched what they ate," or neither dieted nor "watched what they ate."

Of three hundred forty-five subjects sampled, $28 \%$ desired thinness only, $23 \%$ desired health only, $22 \%$ desired both thinness and health, and $26 \%$ desired neither thinness nor health. Seventy-two percent of subjects reported body weight dissatisfaction while $16 \%$ reported using unhealthy food management behaviors. 
Using the statistical process of discriminate analysis, $51.6 \%$ of subjects were correctly classified into groups desiring thinness and/or health by a combination of predictor variables that included weight perception accuracy, food management group, religiosity, father's education level, and self-esteem group. Only weight perception accuracy and food management group were found to be significant individual predictors, but their Eigenvalues of 0.38 and 0.24 indicated a low degree of predictive power.

The low predictive power of the variables may have been due to incomplete or inaccurate separation of subjects in dependent variables groups. The data indicate that an additional group of subjects motivated by desire for appearance (but not thinness) may have been extrapolated from the other groups. Separation of girls who desired thinness from girls who were naturally thin may have also strengthened predictive power. The data on desire for health indicate that female adolescent concepts of health may be multidimensional. Further research is needed to clarify how female adolescents view health as it relates to diet, lifestyle, food management behavior, and body image. 


\section{CURRICULUM VITAE}

I was born in New York City, graduated from the Bronx High School of Science in 1969, and received a Bachelor of Science degree in biology from the State University of New York at Stony Brook in 1973. I began a doctoral program in microbiology at West Virginia University in 1974 and completed three years of that program. I met my husband while I was in graduate school. We were married in 1976, had our first daughter in 1977 and our second daughter in 1984.

Between 1978 and 1984, I worked as a full-time and part-time research assistant in basic science research at West Virginia University Medical Center. I studied midwifery during the same period and was registered with the Midwives' Alliance of West Virginia (MAWV) in 1981 and with the Midwives' Alliance of North America in 1990.

In 1984, due to my desire to be more home-based for the sake of my children, I discontinued my work as a research assistant and chose to work at home for a friend who owned a small musical crafts business. I practiced midwifery until 1991 and worked at the crafts

business until 1996, both on a part-time basis. I remain active in MAWV and have served as president since 1996.

I was accepted to the Master of Science program in the Division of Family and Consumer Sciences (formerly the Division of Family Resources) at West Virginia University in 1994, became a member of the honor society of Gamma Sigma Delta in 1997, a registered dietitian in April, 1998, and began work as a dietitian at the United Affiliated Center for Developmental Disabilities in June, 1998. 


\title{
DESIRE FOR THINNESS AND DESIRE FOR HEALTH AMONG EIGHTEEN AND NINETEEN YEAR OLD FEMALE ADOLESCENTS
}

By

Monica Andis

\author{
A THESIS \\ Submitted to \\ West Virginia University \\ in partial fulfillment of the requirements \\ for the degree of \\ Master of Science
}

APPROVAL OF EXAMINING COMMITTEE

Carol Markstrom, Ph.D.

Shirley Lazorchak, Ph.D.

Date

Mary K. Head, Ph.D., Chair 